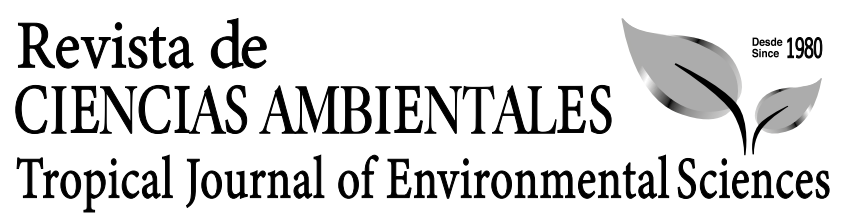

Revista de Ciencias Ambientales (Trop J Environ Sci)

e-ISSN: 2215-3896

(Enero-Julio, 2021) . Vol 55(1): 86-117

DOI: https://doi.org/10.15359/rca.55-1.5

Open Access: www.revistas.una.ac.cr/ambientales e-mail: revista.ambientales@una.ac.cr

Loayza-Aguilar R.

\title{
Evidencia de procesos erosivos en la bahía El Ferrol en Perú, para el periodo 1974-2020
}

\author{
Evidence of erosive processes in El Ferrol Bay, Peru, during the 1974-2020 period
}

\author{
Rómulo Loayza-Aguilar ${ }^{1}$
}

[Recibido: 5 de abril 2020, Aceptado: 26 de agosto 2020, Corregido: 28 de setiembre 2020, Publicado: 1 de enero 2021]

\section{Resumen}

[Introducción]: La bahía El Ferrol enfrenta erosión crítica desde la década de 1970; para contener el efecto destructivo de la zona urbana, se enroca la línea de erosión. [Objetivo]: Describir y analizar el proceso erosivo y plantear escenarios para la aplicación de modelos numéricos. [Metodología]: Revisión y análisis de información bibliográfica, fotografías, cartas fotogramétricas, cartas náuticas, mapas cartográficos, imágenes en Google Earth, y visitas in situ. [Resultados]: Las fuentes de arena proceden del río Lacramarca y el sistema dunar. La bahía ha perdido 6200 m ( $45 \%)$ de playa: $50 \%$ enrocado, $27 \%$ con piedras, $13 \%$ con desmonte y $10 \%$ sin protección. El frente de mayor erosión es la Plaza 28 de julio, en donde el enrocado tiene rompeolas para mitigar los efectos destructivos de la zona urbana. Los factores de erosión son: edificaciones (varadero, almacenes, terrazas, molones de acceso a muelles) sobre la zona supralitoral e intermareal que interfieren el transporte litoral; retención de arena en área de muelles y por lodos orgánicos; el propio enrocado, y traslado forzado, en 2009, de la desembocadura del río Lacramarca unos $1000 \mathrm{~m}$ al sur, que descarga en zona calma. El sistema dunar aporta menos arena por incremento de napa freática. [Conclusiones]: Los factores de mayor impacto son las edificaciones, la retención de arena en el sur por reubicación de río, y el enrocado. Para permitir el transporte litoral de arena, se debe retornar la desembocadura del río a la posición de 2009 y retirar la infraestructura abandonada. Se plantean escenarios de modelación numérica para establecer un plan de recuperación.

Palabras clave: Arena; muelles; río Lacramarca; sistema dunar; transporte litoral.

\section{Abstract}

[Introduction]: El Ferrol bay has faced critical erosion since the 1970s; in order to contain the destructive effect of the urban area, the erosion line has been covered by rock. [Objective]: Describe and analyze the erosive process and propose scenarios to implement numerical models. [Methodology]: Bibliographic information, photographs, photogrammetric charts, nautical charts, cartographic maps, and Google Earth images were reviewed and analyzed, and on-site visits were conducted. [Results]: The sources of sand come from the Lacramarca River and the dune system. The bay has lost $6200 \mathrm{~m}(45 \%)$ of the beach: $50 \%$ rocky, $27 \%$ with stones, $13 \%$ with clearing, and $10 \%$ without protection. The front with the greatest erosion is Plaza 28 de Julio, where breakwaters mitigate the destructive effects on the urban area. Erosion factors include buildings (dry dock, warehouses, terraces, dock access structures) on the supralittoral and intertidal zone that interfere with the coastal transport; retention of sand in the dock area by organic sludge; the rock itself; and the forced transfer of the Lacramarca River mouth in 2009 about $1000 \mathrm{~m}$ to the south, debouching onto a calm zone. The dune system contributes with less sand by increasing the

1 Docente, Escuela de Biología en Acuicultura, Universidad Nacional del Santa (UNS), Perú; rloayza@uns.edu.pe, https://orcid.org/0000-0002-1247-8277

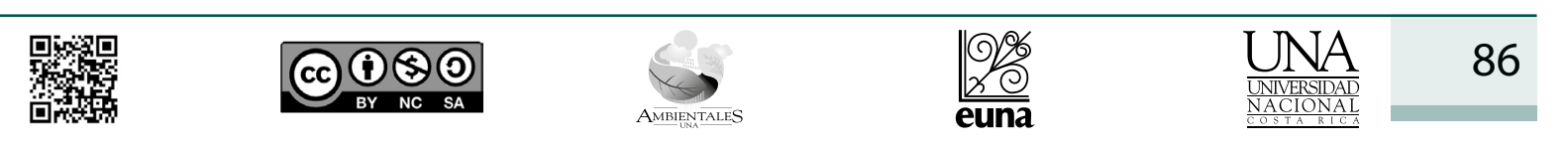




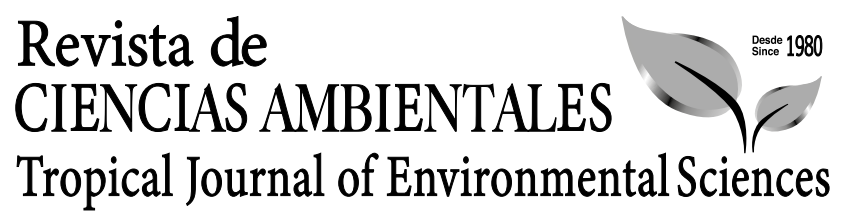

Revista de Ciencias Ambientales (Trop J Environ Sci) e-ISSN: 2215-3896 (Enero-Julio, 2021) . Vol 55(1): 86-117 DOI: https://doi.org/10.15359/rca.55-1.5

Open Access: www.revistas.una.ac.cr/ambientales e-mail: revista.ambientales@una.ac.cr Loayza-Aguilar R.

water table. [Conclusions]: The factors with the greatest impact are buildings, retention of sand in the south due to river relocation, and the rockfall. To allow the littoral transport of sand, the river mouth must be returned to the 2009 location and the abandoned infrastructure must be removed. Scenarios for numerical modeling are proposed to establish a recovery plan.

Keywords: coastal transport; docks; dune system; Lacramarca river; sand.

\section{Introducción}

La erosión costera afecta aproximadamente el $70 \%$ de las costas del mundo (Prasad y Kumar, 2014) y podría aumentar, ya que en los $25 \mathrm{~km}$ de ella vive el $20 \%$ de la población mundial. La erosión es un proceso natural de retroceso de la línea costera en un contexto de déficit sedimentario, en un periodo amplio (Comisión Europea, 2005); sin embargo, por tratarse de microambientes frágiles donde fácilmente el uso humano introduce desequilibrio (Rodríguez y Beltrán, 2012) es una amenaza geológica en zonas con uso intensivo del espacio físico (Correa et al., 2007).

La mayor parte de la erosión se produce por el desvío de sedimentos en presas, supresión de canteras en lechos de ríos, construcción de presas en ríos, edificación de diques y espigones en la línea costera y, en estos últimos 30 años en todo el mundo, por la rápida construcción de puertos relacionados con pesca, turismo, marinas, minería de gas y extracción de arena (Williams et al., 2017).

El inadecuado conocimiento de los procesos sedimentarios ha conducido a la adopción de medidas inapropiadas para mitigar la erosión costera, ya que, en algunos casos, se resuelven los problemas localmente, pero afectan otras zonas y alcanzan decenas de kilómetros (Comisión Europea, 2005), como en Cancún (México) (Guido et al., 2009), el 21.8-30 \% de las costas del Caribe continental colombiano (Ricaurte-Villota, 2015), las playas de Cobo y Mar Chiquita (Buenos Aires, Argentina) (San Martin et al., 2015). La erosión costera en Perú ocurre desde Tumbes hasta la bahía de Paracas (Polar, 2016); la más importante es la de la bahía Miraflores en Lima (Guzmán, s. f.), en Trujillo (Rodríguez-Alza et al., 2016) y el caso de la bahía El Ferrol, propósito del presente estudio.

La bahía El Ferrol significó, para la población local, tanto fuente de alimentos como espacio recreacional y, luego de la construcción del Hotel Chimú (1945-49), se proyectaba el turismo industrial en la bahía. A mediados de la década de 1950, en su litoral se inició el desarrollo de 2 de las industrias más grandes del Perú: pesquera y siderúrgica, pero sin planificar, propiciando una descontrolada expansión (Oficina Nacional de Evaluación de Recursos Naturales [ONERN], 1972). La primera llegó a operar 31 fábricas de harina y aceite de pescado (Kuramoto, 2005), al igual que 25 plantas conserveras (Sulmont, 2006), $85 \%$ concentradas en el parque industrial pesquero 27 de Octubre (Comisión Técnica Multisectorial [CTM], 2012), con lo cual se ocupan las zonas supralitoral e intermareal centro-norte, en donde se construyeron algunas fábricas, muelles (agrupados en el 27 Octubre), un astillero, un varadero, molones de acceso a muelles,

\begin{tabular}{|c|c|c|c|c|c|}
\hline 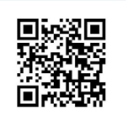 & (c) (i) (5) & $\theta_{\text {AMBIENTALS }}^{6}$ & $\frac{10 \%}{\frac{9}{2}}$ & $\frac{\text { UNA }}{\frac{\text { UNIVERSIDAD }}{\text { UNACIONAL }}}$ & 87 \\
\hline
\end{tabular}




\section{Revista de CIENCIAS AMBIENTALES Tropical Journal of Environmental Sciences}

Revista de Ciencias Ambientales (Trop J Environ Sci) e-ISSN: 2215-3896 (Enero-Julio, 2021) . Vol 55(1): 86-117 DOI: https://doi.org/10.15359/rca.55-1.5 Open Access: www.revistas.una.ac.cr/ambientales e-mail: revista.ambientales@una.ac.cr Loayza-Aguilar R.

canales de desagüe artesanales, tuberías. Este modo de intervenir ocasionó un proceso de erosión que desapareció $6 \mathrm{~km}$ de playa, entre la Empresa Nacional de Puertos (ENAPU) y Petroperú; ahora se utiliza enrocados y desmontes para contenerlo. Por eso, este proceso es diferente a cualquier otro, por citar, como en la bahía Ag. Ioannis, Pilio (Grecia) entre 2012-13 (Tsoukala et al., 2015), Playa Katerini (Grecia) (Kombiadou et al., 2012) y bahía de Giardini Naxos (Italia) (Lanza y Randazzo, 2011). La situación fue agravada por la ausencia de una gestión costera en la bahía El Ferrol. El Perú recién, desde el 2016, cuenta con Lineamientos para el Manejo Integrado de las Zonas Marino Costeras (Ministerio del Ambiente [MINAM], 2016).

No obstante, aun con el tiempo transcurrido y considerando que los problemas derivados de la erosión en la zona centro-norte de la bahía El Ferrol son críticos (Ramos, 2017), no se han podido tomar acciones para solucionar el conflicto, como las propuestas, por ejemplo, por la CTM (2012). Es propósito de este trabajo describir y analizar la situación actual que perturba la bahía por acción erosiva, la cual viene desarrollándose desde mediados de los años 1970 y plantear una serie de escenarios para la aplicación de modelos numéricos. Así como también con el afán de permitir, en el largo plazo, formular estrategias y alternativas para la recuperación del proceso erosivo, constituir un marco regulatorio para las actividades portuarias y prever los impactos debido al incremento del nivel medio del mar ( $\mathrm{nmm}$ ) por el calentamiento global.

\section{Metodología}

\subsection{Localización de la zona de estudio}

La bahía se localiza en la provincia del Santa (Ancash, Perú), entre las coordenadas $78^{\circ} 44^{\prime} \mathrm{W}$ a $78^{\circ} 33^{\prime} \mathrm{W}$ y $9^{\circ} 03^{\prime} \mathrm{S}$ a $9^{\circ} 11^{\prime} \mathrm{S}$; comprende los distritos de Chimbote y Nuevo Chimbote (Figura 1). Se caracteriza por un clima templado, desértico, con temperatura ambiente de $21.0^{\circ} \mathrm{C}$ (máx. $24.1^{\circ} \mathrm{C}$ y $\min .16 .1^{\circ} \mathrm{C}$ ) y un nivel pluviométrico entre 0.9 y $1.85 \mathrm{~mm} \mathrm{mes}^{-1}$ (ONERN, 1972).

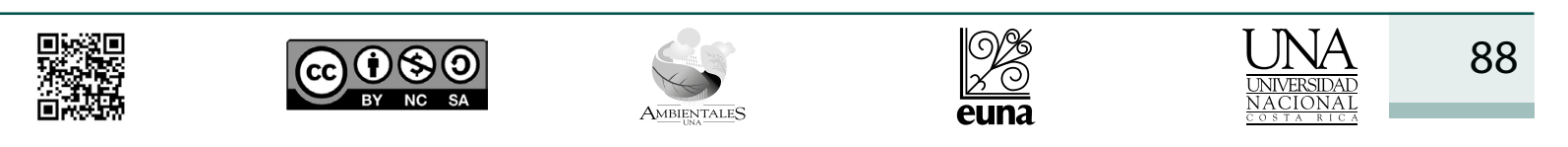




\section{Revista de CIENCIAS AMBIENTALES Tropical Journal of Environmental Sciences}

Revista de Ciencias Ambientales (Trop J Environ Sci) e-ISSN: 2215-3896 (Enero-Julio, 2021) . Vol 55(1): 86-117 DOI: https://doi.org/10.15359/rca.55-1.5 Open Access: www.revistas.una.ac.cr/ambientales e-mail: revista.ambientales@una.ac.cr Loayza-Aguilar R.

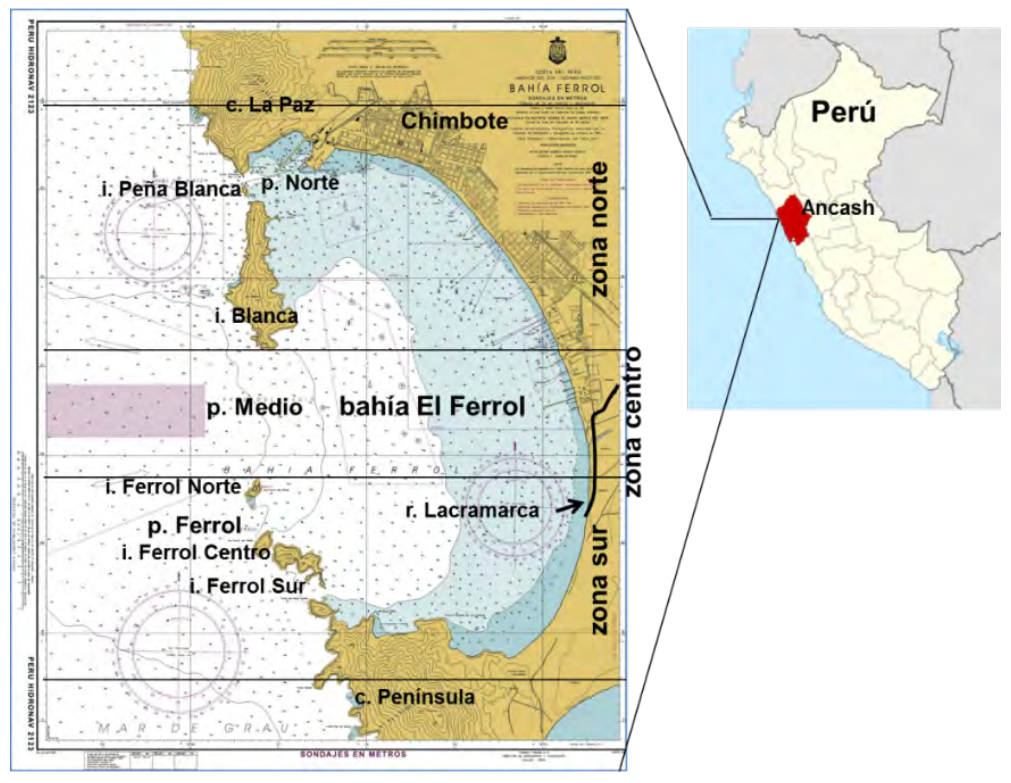

Figura 1. Localización geográfica de la bahía El Ferrol (adaptado de la Dirección de Hidrografía y Navegación [DHN], 2009 y Ramos, 2017)

Figure 1. Geographical location of El Ferrol bay (adapted from the Directorate of Hydrography and Navigation [DHN], 2009 and Ramos, 2017)

\subsection{Descripción de la zona de estudio}

La bahía (Figura 1) es semicerrada, con $11.19 \mathrm{~km}$ de largo, $6.57 \mathrm{~km}$ de ancho, $15 \mathrm{~km}$ de orilla de playa (DHN, 2003) y un área de $75.518 \mathrm{~km}^{2}$ (Tresierra et al., 2007). Está definida por los cerros Península (al sur) y La Paz (al norte), así como por la presencia de 4 de islas: Ferrol del Sur, Ferrol del Centro, Ferrol del Norte, entre 84 y 123 m de altitud, y la Isla Blanca de $204 \mathrm{~m}$ de altitud, que la protegen de los vientos, marejadas y tsunamis. Posee 3 canales de comunicación con el mar abierto, de sur a norte, respectivamente, Paso del Ferrol de 760 m, Paso del Medio de 2700 m y Paso del Norte de 560 m (DHN, 1979; Guzmán, 2006a). En el Paso del Norte, entre la Isla Blanca y el cerro La Paz, se encuentra el islote Peña Blanca de $240 \mathrm{~m}$ de longitud, que restringe la comunicación con el mar abierto en un $50 \%$.

El perfil batimétrico presenta la isobata de $5 \mathrm{~m}$ a unos $140 \mathrm{~m}$ de la línea de orilla en la zona norte, y entre 300 y $600 \mathrm{~m}$ en la zona sur; la isobata de $10 \mathrm{~m}$ en el centro, y profundidades entre 25-30 m en el Paso del Medio (DHN, 2008, 2016).

Los sedimentos predominantes son fango en la zona norte, fango-arenoso en la zona sur, fango-grumoso en la zona de muelles del 27 de Octubre, arena gruesa frente a la descarga del río Lacramarca; se ubican espacios con mayor carga orgánica (10-11\%), en el borde de la zona norte y frente al 27 de Octubre (Tresierra et al., 2007). Estas características son atribuibles al pasivo

\begin{tabular}{|c|c|c|c|c|}
\hline 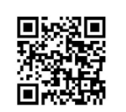 & (c) (i) () & $\underset{\text { AMBEFIAIIES }}{\longrightarrow}$ & $\frac{\sigma \%}{\text { euna }}$ & 89 \\
\hline
\end{tabular}




\section{Revista de CIENCIAS AMBIENTALES Tropical Journal of Environmental Sciences}

de lodos de $54.7 \times 10^{6} \mathrm{~m}^{3}$ (Guzmán et al., 2002). El frente litoral, entre ENAPU y el extremo sur, era una sola playa abierta de $15 \mathrm{~km}$, con zona intermareal amplia y sustrato constituido por arena blanca, fina, y arena gruesa de color rojizo debido a la presencia de óxido de hierro. El perfil de playa, hasta antes de ser perturbada, mantenía el equilibrio entre los periodos de sedimentación (verano) y erosión (invierno) (Ramos, 2010). El extremo más septentrional de la playa era interrumpido por el cerrito Colorado (Figura 2a), de unos $180 \mathrm{~m}$ de largo por $40 \mathrm{~m}$ de ancho.

Del análisis de aerofotos de 1943 y 1961 (Figura 2), se aprecia que la línea de costa estuvo asociada a un sistema dunar, interrumpido por áreas hidromórficas (sistema de humedal). Lamentablemente, no existe información sobre la dinámica interactiva entre estos sistemas, solo de un área de 2825 ha denominada pampa Alconcillo, que comprende el istmo ubicado en el sur (ONERN, 1972), única fuente de arena para la bahía, por acción eólica.

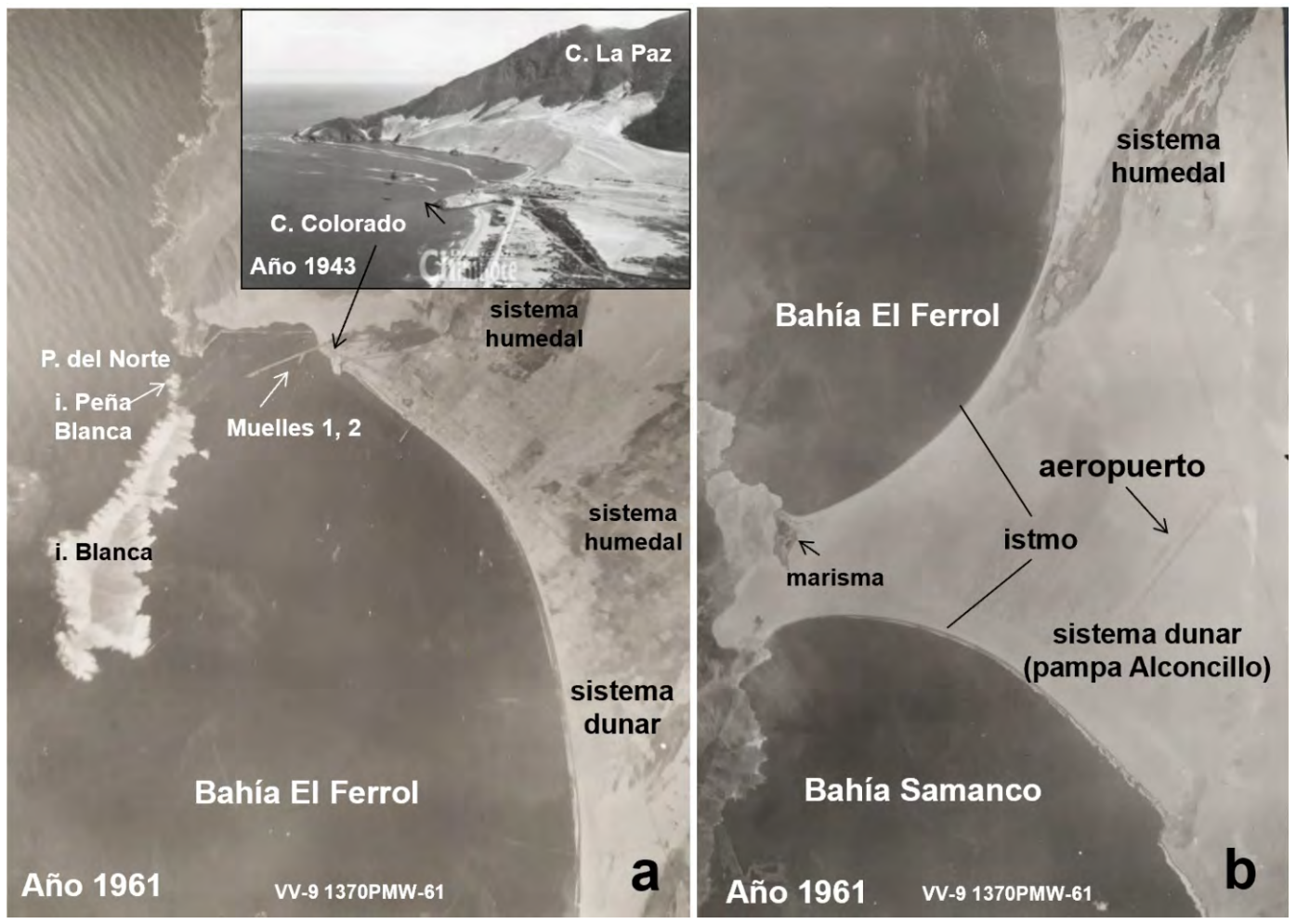

Figura 2. Descripción del sistema dunar y su relación con el aporte de arena a la bahía El Ferrol: a) norte-centro de la bahía, b) sur de la bahía (Aerofotografía 1370PMW-1961)

Figure 2. Description of the dune system and its relationship with the contribution of sand to El Ferrol bay: a) north-center of the bay, b) south of the bay (Aerial photography 1370PMW-1961)

El río Lacramarca se caracteriza por tener cauce seco debido a la ausencia de nevados y lagunas en la cuenca alta, cargando, en momentos de alta precipitación estacional, por encima de los 2000 msnm (Sánchez et al., 2008); sus aguas son inflitradas en la pampa El Toro, antes de su

\begin{tabular}{|c|c|c|}
\hline 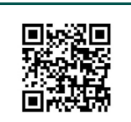 & (c) (i) (;) (2) & 90 \\
\hline
\end{tabular}




\section{Revista de CIENCIAS AMBIENTALES Tropical Journal of Environmental Sciences}

Revista de Ciencias Ambientales (Trop J Environ Sci) e-ISSN: 2215-3896 (Enero-Julio, 2021) . Vol 55(1): 86-117 DOI: https://doi.org/10.15359/rca.55-1.5

Open Access: www.revistas.una.ac.cr/ambientales e-mail: revista.ambientales@una.ac.cr Loayza-Aguilar R.

desembocadura (ONERN, 1972). Durante el evento El Niño de 1972, la desembocadura del río ubicada al sur de la plaza 28 de Julio fue trasladada al sur de la bahía y, a partir de ese momento, colecta aguas de regadíos de la zona agrícola y arrastra arena a la bahía.

Las mareas son semidiurnas, con amplitud de $0.7 \mathrm{~m}$, alcanzan $0.94 \mathrm{~m}$ en mareas de sizigia (Teves, 1999), las cuales generan corrientes con valores máximos en el Paso del Medio de $15 \mathrm{~cm}$ $\mathrm{s}^{-1}$; sin embargo, en promedio, las velocidades de estas corrientes son muy bajas, comparadas con otras bahías con promedios superiores a $30 \mathrm{~cm} \mathrm{~s}^{-1}$ (Guzmán, 2006b).

Los vientos, entre 5-8.1 $\mathrm{m} \mathrm{s}^{-1}$ (Guzmán, 2014), con ráfagas eventuales de 15-17 $\mathrm{m} \mathrm{s}^{-1}$ (Teves, 1999), ejercen poca influencia en la generación de corrientes en la bahía, propiciando circulación lenta, con corrientes promedio entre $6.5-14 \mathrm{~cm} \mathrm{~s}^{-1}$, y máxima de $38 \mathrm{~cm} \mathrm{~s}^{-1}$ (Guzmán, 2014). Debido a las condiciones batimétricas, por refracción y difracción, las olas disminuyen su velocidad (Ramos, 2017) y, gradualmente, el frente de estas se orienta hacia el norte, girando en sentido horario, rompiendo perpendicularmente la línea de costa (Teves, 1999). La altura promedio de esas olas es de 0.5-1 m y 1.5-2 m en condiciones extremas, con mayor incidencia en la zona ubicada entre el casco urbano y el barrio Miramar; se halla menor incidencia en la zona sur, con olas menores a $0.5 \mathrm{~m}$ (DHN, 2019). La frecuencia anual del oleaje irregular o braveza de mar es entre 15-25\% (Teves, 1999). Por su orientación hacia el oeste, la bahía está influenciada por las olas Swell del hemisferio sur, con periodos de 10-25 segundos (DHN, 2013).

Hasta el inicio de la industria pesquera, la bahía poseía extensa playa con 35-45 $\mathrm{m}$ de zona intermareal y pendiente moderada en sus $15 \mathrm{~km}$ (Figura 3).

\begin{tabular}{|c|c|c|c|c|c|}
\hline 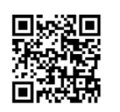 & (c) (i) () () & $\underset{\text { AMBEIETILES }}{8}$ & $\frac{1 \%}{2 \%}$ & 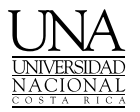 & 91 \\
\hline
\end{tabular}




\section{Revista de CIENCIAS AMBIENTALES Tropical Journal of Environmental Sciences}
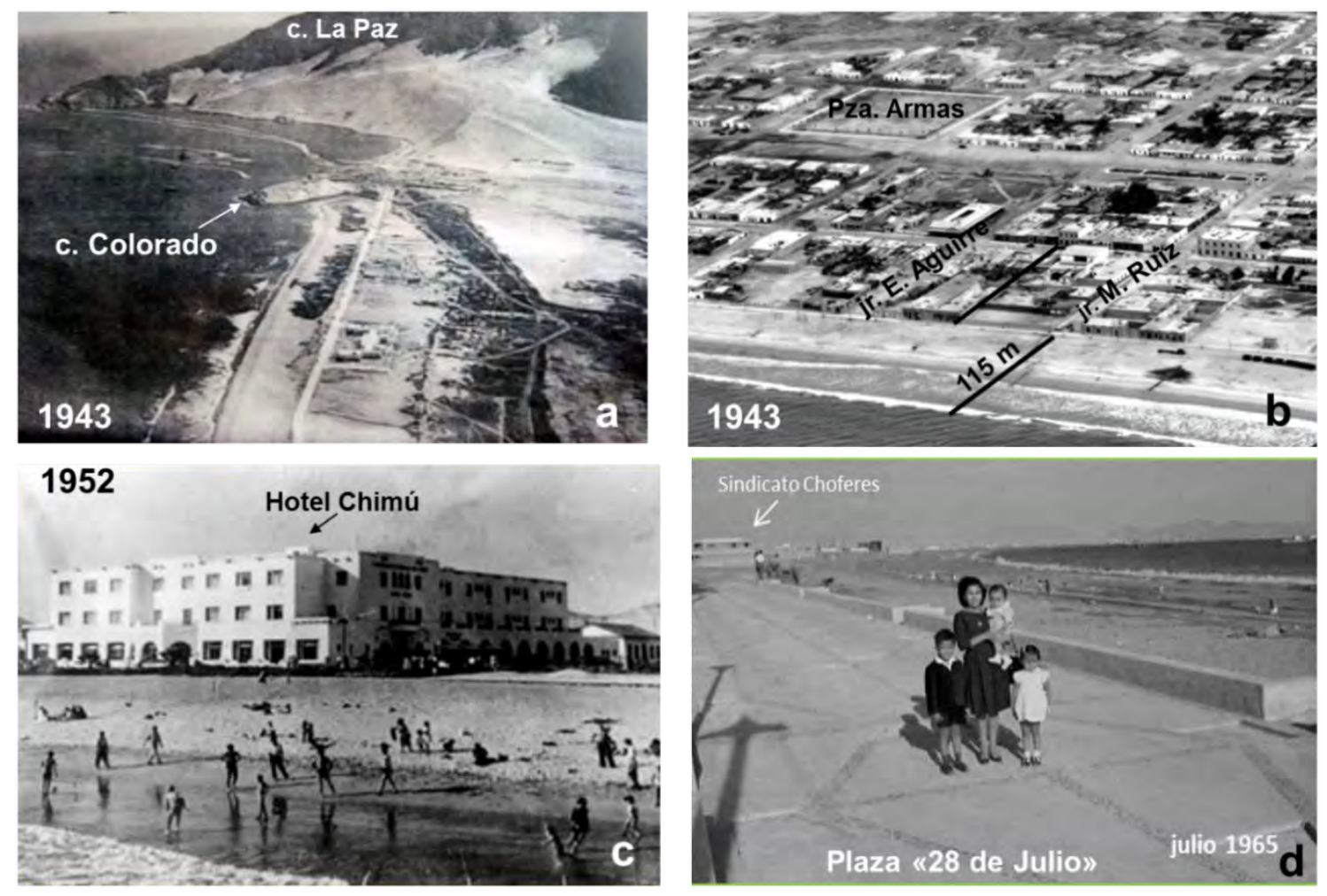

Figura 3. Tamaño de las playas de la bahía El Ferrol antes del inicio del proceso erosivo (fotos del Servicio Aerofotográfico Nacional, archivo virtual Miguel Koo Chía)

Figure 3. Size of the beaches of El Ferrol bay before the start of the erosive process (potos from National Aerophotographic Service, virtual archive Miguel Koo Chía)

\subsection{Estrategia metodológica}

Para elaborar este trabajo, se ha revisado y analizado material bibliográfico; aerofotografías VV AST-9 1370PMW M21 2476, 2478, 2479, 2517, 2518; fotografías del Servicio Aerofotográfico Nacional, archivo virtual Miguel Koo Chía y Loayza (1998, 2002a); cartas náuticas (Perú Hidronav 1313; Perú Hidronav 2123); mapas cartográficos (Perú HIDRONAV 1313); mapas geológico y minero de las cuencas de los ríos Santa, Lacramarca, Nepeña, Casma, Culebras y Huarmey, y de transportes de los valles de Santa y Lacramarca (ONERN, 1972); imágenes disponibles en Google Earth; planos de la ciudad de Chimbote; entrevistas con funcionarios y especialistas locales, y vistas de campo, en varias oportunidades, de todo el litoral con erosión y el sur de la bahía, las últimas entre enero y febrero de 2020, realizando tanto registro fotográfico como medidas de zona intermareal y de enrocados. Para la presentación y discusión de los resultados, se ha considerado la zonificación de la bahía utilizada por Ramos (2017) (Figura 1).

\begin{tabular}{|c|c|c|}
\hline 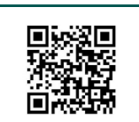 & (c) (1) () (2) (2) & 92 \\
\hline
\end{tabular}




\section{Revista de CIENCIAS AMBIENTALES Tropical Journal of Environmental Sciences}

Revista de Ciencias Ambientales (Trop J Environ Sci) e-ISSN: 2215-3896 (Enero-Julio, 2021) . Vol 55(1): 86-117 DOI: https://doi.org/10.15359/rca.55-1.5

Open Access: www.revistas.una.ac.cr/ambientales e-mail: revista.ambientales@una.ac.cr Loayza-Aguilar R.

\section{Resultados y discusión}

\subsection{Proceso erosivo}

En la bahía se desarrollan dos procesos perturbadores: a) fuerte erosión en la zona norte, entre ENAPU y Petroperú (Figura 1) (CTM, 2012), y b) sedimentación en la zona centro-sur (Ramos, 2017).

Es muy escasa la información sobre el incremento del nivel medio del mar (nmm) en el Perú, menos aún local, que permita vincular esta variable como causa de erosión en la bahía. Takahashi et al. (2014) señalan frente a Lima una tendencia (1993-2000) de reducción del nmm de hasta $-6 \mathrm{~mm}$ año ${ }^{-1}$, debido a la variabilidad interdecadal de los vientos alisios. Adicionalmente, en la base del istmo se desarrolla una marisma (Figura 2b), tipo mareal, que no ha variado, ya que en 1961, 1980 y 2016 (Aerofotografía VV AST 1370PMM; DHN, 1980; DHN, 2016) ha ocupado, respectivamente, el 61, 70 y $63 \%$ del ancho del istmo. Por ello, se estima que el incremento del nmm no sería un factor en el proceso erosivo.

Otros factores que no habrían tenido influencia en el origen de erosión en la bahía son los vientos, al no encontrar evidencias de cambios entre 1972-1991 (Larrea, 1994); el sistema dunar del istmo, que se mantenía intacto (Figura 2), y, de igual modo, la dinámica del río Lacramarca, que solo incorporaba material sedimentario en momentos de alta precipitación (ONERN, 1972).

El Niño Oscilación Sur (ENOS) influye en las condiciones climatológicas interanuales en la cuenca del océano Pacífico, con manifestación cálida en el Pacífico Oriental, particularmente en la costa norte de Perú (Takahashi, 2017), propiciando lluvias, incremento de la descarga de ríos, inundaciones, formación y reactivación de quebradas; se manifiesta con diferentes intensidades, los más fuertes son de los últimos 100 años, los ocurridos en 1925, 1982-1983, 1997-1998 y 2017 (Figura 4) (Takahashi, 2017). El evento 1972-1973 originó lluvias en la cuenca del río Lacramarca, con caudal de $60 \mathrm{~m}^{3} \mathrm{~s}^{-1}$ y aporte sedimentario a la bahía de $6134.4 \mathrm{t}$ día ${ }^{-1}$, y el suceso 1997-1998 generó caudales de $280 \mathrm{~m}^{3} \mathrm{~s}^{-1}$, con descarga sedimentaria de $36288 \mathrm{t} \mathrm{día}^{-1}$ (Ramos, 2017). Como se puede apreciar, desde el punto de vista sedimentario, los acontecimientos El Niño no serían la causa de erosión en la bahía y, más bien, en estos últimos 40 años, debido a la mayor frecuencia e intensidad, aportan sedimento. Desde la perspectiva oceanográfica, El Niño produce un aumento de la altura de las olas en aguas profundas, por tanto, los niveles de run-up en las playas y las mareas se elevan con la posibilidad de formar erosión (Allan y Komar, 2006), pero, terminado el hecho, la dinámica sedimentaria restablece su equilibrio, por lo que tampoco serían el motivo de erosión.

\begin{tabular}{|c|c|c|c|c|}
\hline 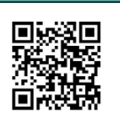 & (c) (i) (5) () & 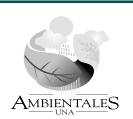 & $\frac{O \%}{2}$ & 93 \\
\hline
\end{tabular}




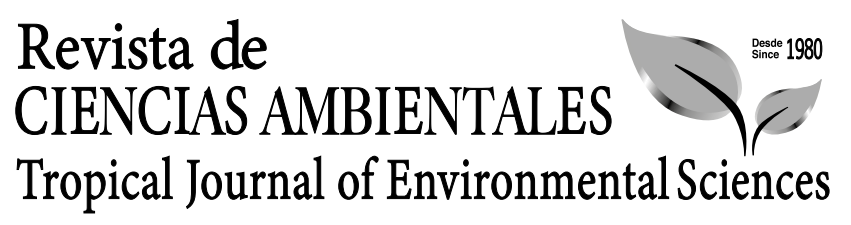

Revista de Ciencias Ambientales (Trop J Environ Sci) e-ISSN: 2215-3896 (Enero-Julio, 2021) . Vol 55(1): 86-117 DOI: https://doi.org/10.15359/rca.55-1.5 Open Access: www.revistas.una.ac.cr/ambientales e-mail: revista.ambientales@una.ac.cr Loayza-Aguilar R.

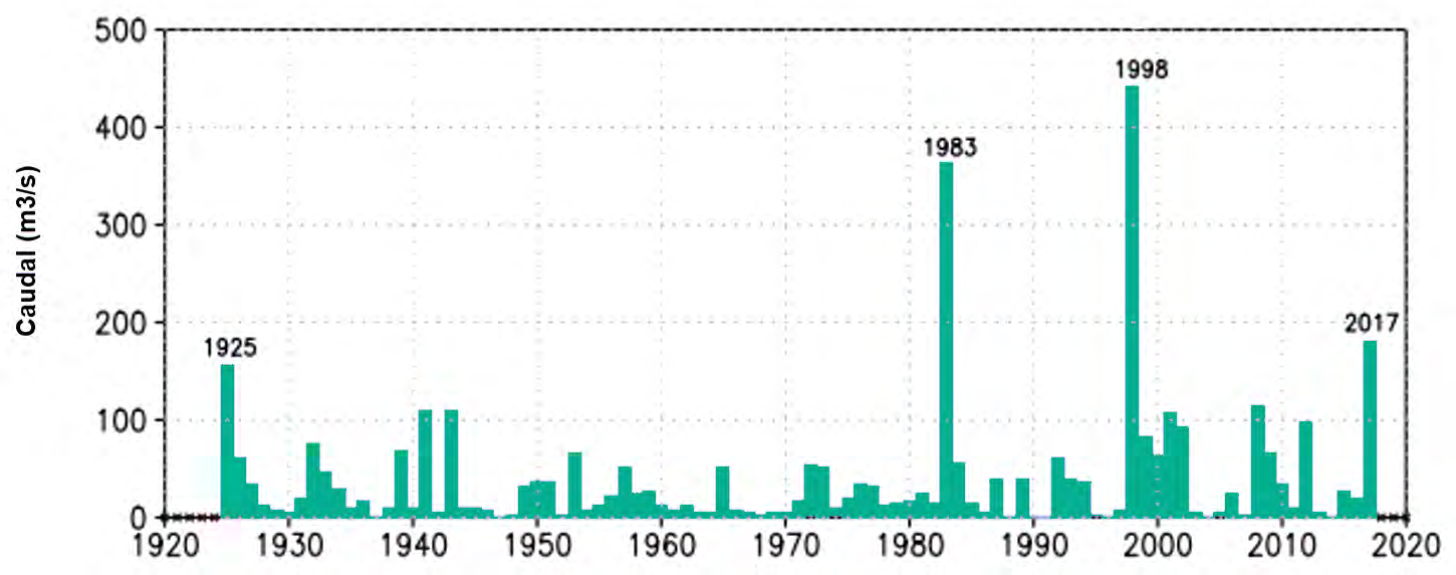

Figura 4. Caudal promedio anual (enero-diciembre) del río Piura, para el periodo 1925-2017 (Takahashi, 2017). Figure 4. Average annual flow (January-December) of the Piura river, for the period 1925-2017 (Takahashi, 2017).

Ramos (2017) considera que la variación sedimentaria en la bahía es principalmente antropogénica, relacionada con industria, pesquería, construcción de infraestructura, así como con la presencia del río Lacramarca y sedimentos eólicos. El ingeniero Leopoldo Gonzáles señala que en 1962, frente al casco urbano de la ciudad, la amplitud de playa era 60-70 m, pero en 1974 el mar amenazaba la destrucción de viviendas y edificios ubicados en el Malecón Grau, lo cual motivó que en 1976-77 se erigiera un enrocado de 820 m entre las avenidas Guillermo Moore y José Gálvez. Livesey \& Henderson Consulting Engineers [LHCE] (1972) determinaron que entre el varadero INASSA y la plaza 28 de Julio la velocidad de erosión en 1969-71 era de $5 \mathrm{~m}$ año ${ }^{-1}$, sin embargo, en el lapso 1998-2000, este valor, entre la plaza 28 de Julio y el norte del barrio Miramar, espacio aún no enrocado, pero el de mayor impacto por oleaje, era 10-12 $\mathrm{m}$ año-1 (Loayza, 2002a). Ramos (2017), entre 2003-2017 registró erosión de las zonas centro-sur (50-40 m).

\subsection{Evidencias e impactos del proceso erosivo}

Una característica notable de la bahía fue el tamaño de sus playas, en promedio $100 \mathrm{~m}$ de amplitud, con 35-45 m de zona intermareal (Figura 3), la cual mantenía equilibrada la cantidad de arena que perdía por acción eólica, oleaje y mareas, frente a la que ingresaba por acción eólica, por el lado sur y transitaba a lo largo del litoral (Loayza, 1998, 2002a).

Luego de la construcción del enrocado (Figura 5d), en 1998 la erosión se extendía hasta las instalaciones de Petroperú (Figura 5h). Frente a la plaza 28 de Julio, línea de mayor erosión, había desaparecido la zona intermareal y supralitoral (Figuras 3d y 5b), cambiando el perfil batimétrico (Figura 6); destruía infraestructura de alcantarillado, el edificio del Sindicato de Choferes (Figura 5d) y una manzana de viviendas detrás de este (Figura 5c). Hacia el sur, la

\begin{tabular}{|c|c|c|c|c|c|}
\hline 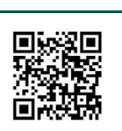 & (c) (1) () (2) & $\Leftrightarrow$ & $\frac{O \mathscr{O O}}{20}$ & 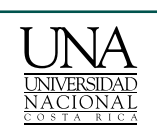 & 94 \\
\hline
\end{tabular}




\section{Revista de CIENCIAS AMBIENTALES Tropical Journal of Environmental Sciences}

Revista de Ciencias Ambientales (Trop J Environ Sci) e-ISSN: 2215-3896 (Enero-Julio, 2021) . Vol 55(1): 86-117 DOI: https://doi.org/10.15359/rca.55-1.5 Open Access: www.revistas.una.ac.cr/ambientales e-mail: revista.ambientales@una.ac.cr Loayza-Aguilar R.

zona intermareal desaparecía progresivamente y la línea de erosión invadía la zona supralitoral (Figuras 5f, $\mathbf{g} \mathbf{y} \mathbf{h}$ ). Para contrarrestar la erosión, se disponía, con frecuencia, de abundante desmonte (Figuras 5d, e, f y g), ya que, producto del oleaje y las mareas, pronto este material quedaba sumergido (Loayza, 1998). Al sur de la plaza 28 de Julio, la erosión destruyó el alcantarillado, tuberías de agua potable, viviendas, edificios, veredas, un centro escolar, lozas deportivas, fábricas, etc. Actualmente, $6200 \mathrm{~m}$ del litoral (45\%) se encuentran erosionados y de ello el 50 $\%$ tiene enrocado clásico, $27 \%$ piedras amontonadas, $13 \%$ con desmonte y $10 \%$ sin protección.

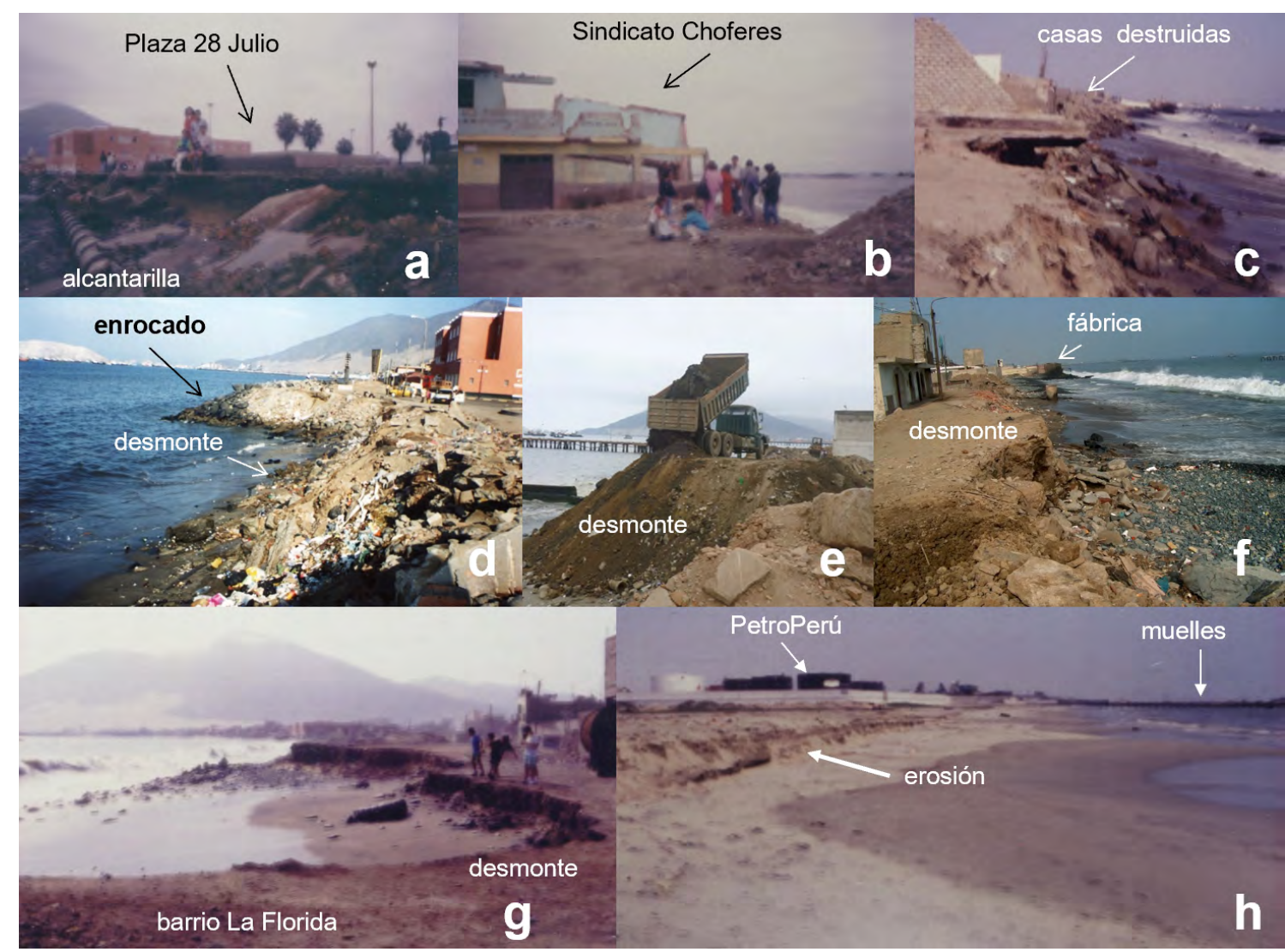

Figura 5. Efectos destructivos del proceso erosivo en la bahía El Ferrol, registrados en 1998 (fotos tomadas de Loayza, 1998, 2002a)

Figure 5. Destructive effects of the erosive process in El Ferrol bay recorded in 1998 (photos taken from Loayza, 1998, 2002a)

\begin{tabular}{|c|c|c|}
\hline 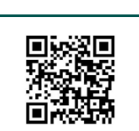 & (c) (1) () (2) (2) & 95 \\
\hline
\end{tabular}




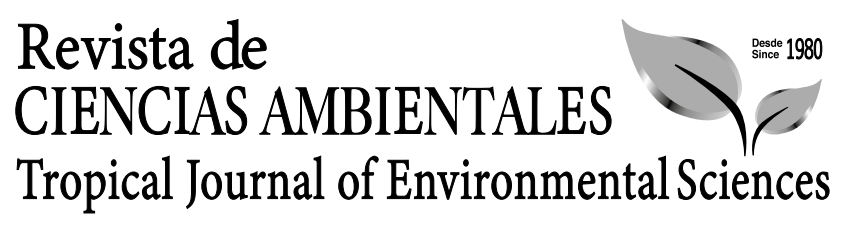

Revista de Ciencias Ambientales (Trop J Environ Sci) e-ISSN: 2215-3896

(Enero-Julio, 2021) . Vol 55(1): 86-117 DOI: https://doi.org/10.15359/rca.55-1.5

Open Access: www.revistas.una.ac.cr/ambientales e-mail: revista.ambientales@una.ac.cr Loayza-Aguilar R.

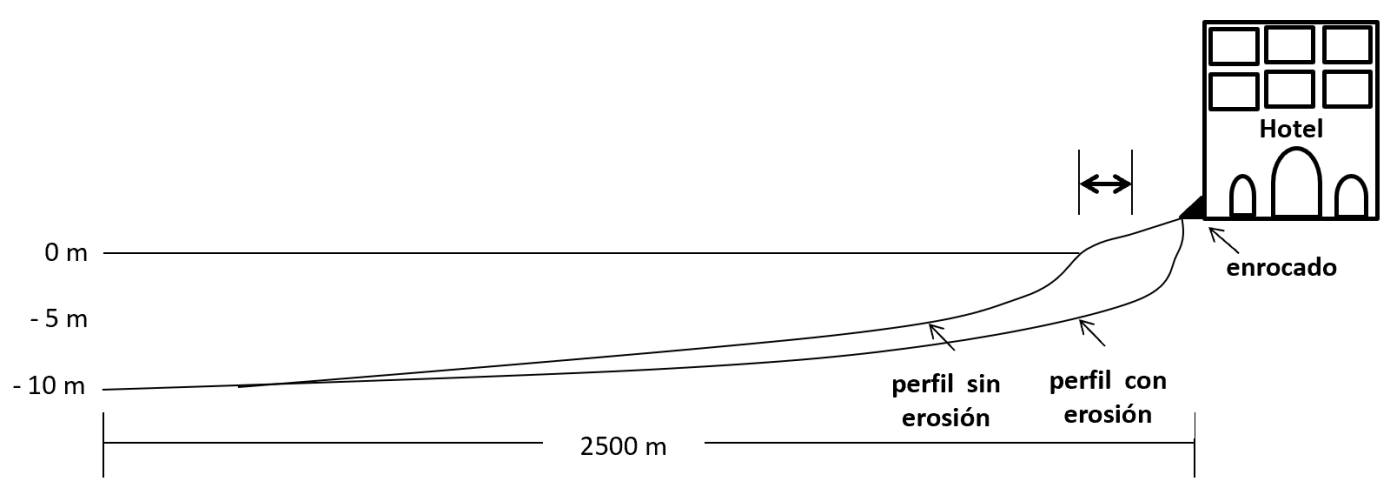

Figura 6. Evolución del perfil batimétrico de la bahía El Ferrol por proceso erosivo, frente al hotel, zona de mayor impacto del oleaje, hasta la isobata de $10 \mathrm{~m}$ ( | ßà | representa el espacio intermareal), tomando como referencia la Figura 3 y DHN (2016).

Figure 6. Evolution of the bathymetric profile of the El Ferrol bay by erosive process, in front of the hotel, the area with the greatest impact of the waves, up to the $10 \mathrm{~m}$ isobaths ( $\mid$ Bà $\mid$ represents the intertidal space), taking as reference Figure 3 and DHN (2016).

La erosión de la zona intermareal ocasionó la desaparición de Donax donax y Emerita ana$\log a$, importantes en la red alimentaria acuática y como recursos pesqueros. También desapareció Ocypode gaudichaudii, crustáceo cuyo nicho ecológico es mantener limpias las playas de restos orgánicos. Socialmente, la población local y turistas dejaron de visitar las playas con motivos de recreación; culturalmente, la población fue perdiendo su vínculo de identidad con la bahía. Cuando las olas golpean el enrocado, se genera spray, lo que afecta las estructuras metálicas, material noble y madera de las viviendas, con pérdidas económicas.

\subsection{Causas del proceso de erosión}

No obstante que el proceso erosivo es crítico, existen escasos estudios sobre dinámica sedimentaria (Guzmán et al., 2002; LHCE, 1972), corrientes marinas (Guzmán, 2006a, 2014; Saavedra y Guzmán, 2003) y modelamiento numérico (DHN, 2019; Guzmán, 2006a, 2014; Ramos, 2014, 2017). Se atribuye como causas del proceso erosivo a los lodos acumulados en el fondo de la bahía y a la construcción de infraestructura (CTM, 2012).

\begin{tabular}{|c|c|c|c|c|c|}
\hline 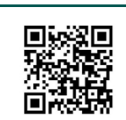 & (c) & $\underset{\text { AMBIENTAIES }}{\infty}$ & 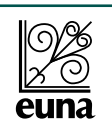 & 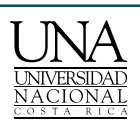 & 96 \\
\hline
\end{tabular}




\section{Revista de CIENCIAS AMBIENTALES Tropical Journal of Environmental Sciences}

Revista de Ciencias Ambientales (Trop J Environ Sci) e-ISSN: 2215-3896 (Enero-Julio, 2021) . Vol 55(1): 86-117 DOI: https://doi.org/10.15359/rca.55-1.5

Open Access: www.revistas.una.ac.cr/ambientales e-mail: revista.ambientales@una.ac.cr Loayza-Aguilar R.

\subsubsection{Por aportes de materia de la industria pesquera}

Todos los efluentes de las fábricas pesqueras eran dispuestos sin tratamiento en la bahía, principalmente en el 27 de Octubre, que concentraba el $85 \%$ de estas (Sánchez et al., 2008). Dichos efluentes contenían trozos de pescado, escamas, sanguaza y agua de cola, con carga de $\mathrm{DBO}_{5}$ de $45000 \mathrm{mg} \mathrm{l}^{-1}$ (Neyra, 2015), equivalente a $40.1 \times 10^{3} \mathrm{t}$ de proteínas y $9551 \mathrm{t}$ de aceite, por año (Basurco (2000); han generado un pasivo de lodos de 54.7 x $10^{6} \mathrm{~m}^{3}$ (Guzmán et al., 2002).

La naturaleza coloidal de los lodos acumulados, principalmente en el 27 de Octubre, con comportamiento viscoelástico, propició la formación de agregados con la arena (Ojeda et al., 2008), hecho que la retuvo. Actualmente, esta condición estaría siendo revertida por las siguientes razones: a) en cumplimiento al Plan Ambiental Complementario Pesquero (Ministerio de la Producción [PRODUCE], 2007) y a los límites máximos permisibles para la industria de harina y aceite de pescado (PRODUCE, 2008), a partir de mayo de 2015, las fábricas dejaron de disponer sus efluentes en la bahía; b) el aporte trascendental de arena a la bahía durante El Niño Costero 2017 ha ocasionado variaciones en la composición granulométrica del fondo: en el 2008, $50 \%$ limoso $+38 \%$ arena-limosa $+17 \%$ arena, y en el 2019, $50 \%$ arena-limosa $+31 \%$ limo-arenoso $+10 \%$ arena $(\mathrm{DHN}, 2019)$, que facilita el transporte de arena hacia el norte.

\subsubsection{Por la construcción de infraestructura}

\subsubsection{Espigones}

Los espigones son construidos para regenerar, estabilizar o crear playas (Suarez, 2001), pero también generan erosión. Entre 1943-45 se construyó el primer espigón en la bahía (Muelle 1), de $974 \mathrm{~m}$ de longitud, con un apéndice (espigón) de 100 m (Muelle 2) (Figura 7a), y entre 1967-

68 se edificó el Muelle 3 (espigón), de $250 \mathrm{~m}$ (Figura 7b); para facilitar las operaciones en este último, en el mismo periodo, se cimentó una plataforma, conocida como molón, que ocupa el cerrito Colorado de 0.72 ha y $200 \mathrm{~m}$ de playa (Figura $7 \mathbf{b}, \mathbf{c}$ ). El molón tiene 13.5 ha, con $670 \mathrm{~m}$ de largo por $250 \mathrm{~m}$ de ancho y un espigón de $200 \mathrm{~m}$, que hacen un total de $870 \mathrm{~m}$ de proyección al mar.

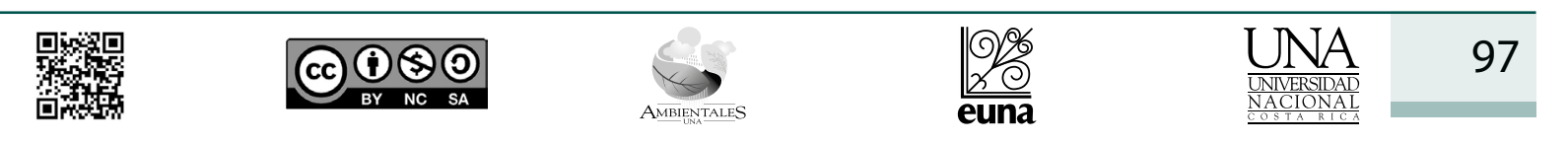




\section{Revista de CIENCIAS AMBIENTALES Tropical Journal of Environmental Sciences}

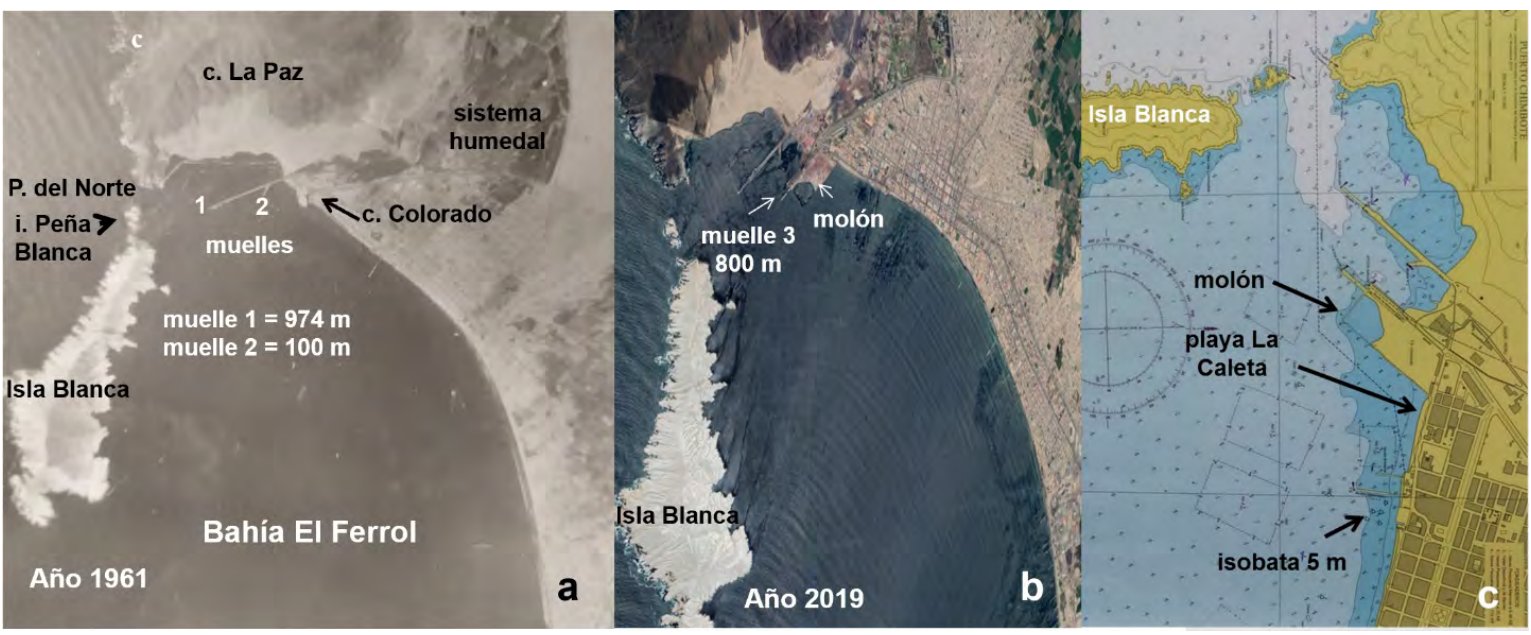

Figura 7. Presencia de espigones en la bahía El Ferrol. a) Aerofotografía 1370PMW-1961, b) Google Earth, octubre 2019, c) DHN (2016).

Figure 7. Presence of breakwaters in El Ferrol bay. a) Aerial photography 1370PMW-1961, b) Google Earth, October 2019, c) DHN (2016).

Los espigones actúan como barrera al tránsito de la arena a lo largo de la playa, modificando las corrientes y cambiando el perfil de esta, al acumular arena en el lado de la dirección de la corriente, y erosión en el sitio opuesto (Tsoukala et al., 2015). Cuando se analiza la carta batimétrica de LHCE (1972), se deduce que, luego de la construcción del molón, la isobata de 3 brazas, ubicada a $400 \mathrm{~m}$, entre 1962-69 se había trasladado unos $700 \mathrm{~m}$ hacia el interior de la bahía, lo que significa acumulación de arena. Tras 84 y 51 años de la presencia de los espigones y examinar las cartas de la DHN (1980, 2009 y 2016), el patrón de comportamiento de la isobata de $5 \mathrm{~m}$ es mantenerse hasta finalizar el molón (Figura 7c). Por déficit sedimentario, la playa La Caleta ha perdido un $66 \%$ de amplitud (Figuras 2, 3 y $7 \mathrm{c}$ ) y ha mantenido este perfil, dada la acumulación de arena que propicia el molón. Si se toma en cuenta la baja velocidad de las corrientes en la bahía, estas, al encontrarse con el molón, no generan una elevación significativa del nivel del aguar, que, de haber ocurrido, habría desaparecido la playa La Caleta; de tal modo, es poco probable que el molón contribuya con el proceso erosivo. No obstante, por su longitud, interfiere en la circulación del agua y el transporte de sedimentos (Figura 7), pues desvía las corrientes hacia el sotavento de la Isla Blanca.

\subsubsection{Muelles}

Desde mediados de 1950, se construyeron muchos muelles, 5 de ellos ubicados en la zona norte: 2 corresponden a Gildemeister y Embarcadero Muelle Pesquero, y 3 están inutilizados (Cuadro 1).

\begin{tabular}{|c|c|c|}
\hline 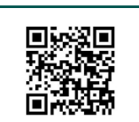 & (c) (i) () () () & 98 \\
\hline
\end{tabular}




\section{Revista de CIENCIAS AMBIENTALES Tropical Journal of Environmental Sciences}

Revista de Ciencias Ambientales (Trop J Environ Sci) e-ISSN: 2215-3896 (Enero-Julio, 2021) . Vol 55(1): 86-117 DOI: https://doi.org/10.15359/rca.55-1.5

Open Access: www.revistas.una.ac.cr/ambientales e-mail: revista.ambientales@una.ac.cr Loayza-Aguilar R.

Cuadro 1. Muelles en desuso ubicados en la zona norte de bahía El Ferrol

Table 1. Disused docks located in the north of El Ferrol bay

\begin{tabular}{|c|c|c|c|c|}
\hline \multirow{2}{*}{ Ubicación } & \multicolumn{3}{|c|}{ Dimensiones } & \multirow{2}{*}{ Descripción } \\
\hline & Largo (m) & Ancho (m) & Área (ha) & \\
\hline $\begin{array}{l}09^{\circ} 05^{\prime} 02^{\prime \prime} \mathrm{S} \\
78^{\circ} 35^{\prime} 09^{\prime \prime} \mathrm{W}\end{array}$ & 102 & 10 & 0.10 & $\begin{array}{l}\text { Abandonado, ubicado a } 170 \mathrm{~m} \text { de tierra. Debe ser } \\
\text { retirado. }\end{array}$ \\
\hline $\begin{array}{l}09^{\circ} 05^{\prime} 21^{\prime \prime S} \\
78^{\circ} 34^{\prime} 41^{\prime \prime} \mathrm{W}\end{array}$ & 290 & 13 & 0.13 & Abandonado, partido en 2. Evaluar su reúso. \\
\hline $\begin{array}{l}09^{\circ} 05^{\prime} 34^{\prime \prime} \mathrm{S} \\
78^{\circ} 34^{\prime} 31^{\prime \prime} \mathrm{W}\end{array}$ & 195 & 7 & 0.11 & $\begin{array}{l}\text { Interrumpido a unos } 10 \mathrm{~m} \text { de tierra. Evaluar su } \\
\text { reúso. }\end{array}$ \\
\hline
\end{tabular}

El Muelle Gildemesiter, de 300 m de longitud, se construyó en 1957 y, más adelante, el muelle desembarcadero Pesquero Artesanal, de $144 \mathrm{~m}$. Estos muelles, sobre pilotes, no interfieren en el transporte litoral de arena. Aquellos en desuso, hechos sobre pilotes, tampoco interrumpen el transporte de arena; pero sí se rediseña el molón de acceso de 2 de ellos, podrían utilizarse en actividades recreacionales como pesca deportiva, paseos en bote, centro de referencia de turismo; estación meteorológica y oceanográfica.

Otros 11 muelles se localizan en el 27 de Octubre (Figura 8a), en $1700 \mathrm{~m}$ de orilla de playa, equivalente a 1 muelle cada $154 \mathrm{~m}$. Estos tienen en promedio $247 \mathrm{~m}$ de largo por $3.5 \mathrm{~m}$ de ancho, y todos se encuentran sobre pilotes. De ellos destaca el Muelle Municipal Centenario, de $800 \mathrm{~m}$ de longitud: 2 cabezos de $150 \mathrm{~m}$ cada uno y $20 \mathrm{~m}$ de ancho, y 2 puentes de 180 y $100 \mathrm{~m}$, respectivamente, sobre pilotes de 0.4 x $0.40 \mathrm{~m}$. Los 2 cabezos tienen 565 pilotes y los 2 puentes 30 , lo que totaliza 595. La profundidad promedio en los cabezos es de $7.5 \mathrm{~m}$, por lo que cada pilote ofrece un área de resistencia al oleaje y corrientes de $3 \mathrm{~m}^{2}$.

Los muelles sobre pilotes son estructuras que permiten el paso de sedimentos y, mayormente, no generan erosión ni sedimentación (Ramos, 2010); sin embargo, lo concreto en el caso de la bahía es que se evidencia constante sedimentación en tales estructuras (Sánchez et al., 2010), corroborada con modelación numérica, al probar el área de muelles con y sin descarga del río Lacramarca (Ramos, 2010). El SIMA-Chimbote — para mantener las operaciones de su muellesiempre ha dragado y hoy, aun cuando la desembocadura en el 2009 fue trasladada a más de 1 $000 \mathrm{~m}$ al sur (Ramos, 2010), se extrae sedimento del sistema syncrolift por medio de bombeo, y es dispuesto en zona intermareal al costado de un muelle en desuso, al sur del Muelle Municipal. Por otro lado, Luis Odar Cumpa y Oscar Barrantes Novoa (com. pers., 2020), funcionarios del Muelle Municipal, señalan que en el periodo 2007-2019 se ha perdido $1 \mathrm{~m}$ de profundidad por sedimentación, aun cuando en el 2012 habían realizado un dragado, en un estrato de material limo-arcilloso de entre 1.8 y $2 \mathrm{~m}$.

\begin{tabular}{|c|c|c|c|c|c|}
\hline 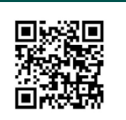 & (c) (i) () () & $\overbrace{\text { AMEREIIIIS }}$ & $\frac{O \%}{2 \%}$ & 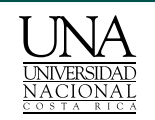 & 99 \\
\hline
\end{tabular}




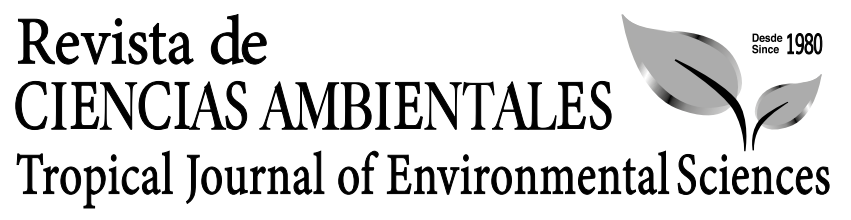

Revista de Ciencias Ambientales (Trop J Environ Sci) e-ISSN: 2215-3896 (Enero-Julio, 2021) . Vol 55(1): 86-117 DOI: https://doi.org/10.15359/rca.55-1.5 Open Access: www.revistas.una.ac.cr/ambientales e-mail: revista.ambientales@una.ac.cr Loayza-Aguilar R.

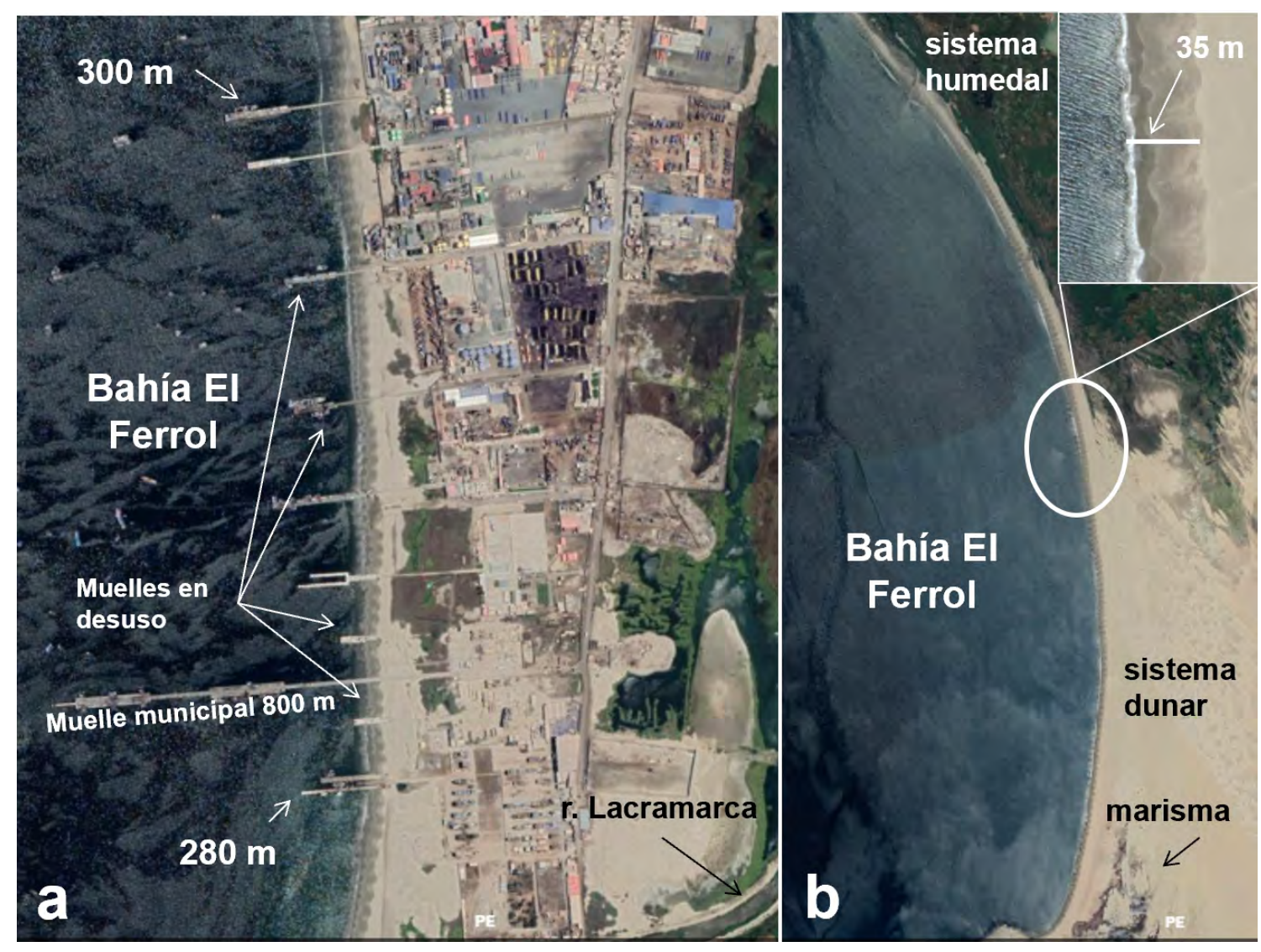

Figura 8. Presencia de muelles en la zona sur de la bahía El Ferrol (imagen de Google Earth, octubre 2019) Figure 8. Presence of piers in the southern area of the El Ferrol bay (Google Earth image, October 2019)

Según la dinámica de isobatas con base en 1897, 1962 y 1969 (LHCE, 1972), la de 5 brazas que en 1897 se encontraba cerca a la orilla, donde se ubican los muelles, luego de la construcción de estos, en 1969 se había trasladado hacia el interior de la bahía; lo que significa acumulación de arena en el área de muelles, y ocurrió antes de que el río Lacramarca fuera reasentado al sur de la bahía. Con los aportes actuales del río, la tasa de retención de arena debe ser mayor.

Al recorrer el litoral sur de la bahía y analizar imágenes de Google Earth, se aprecia que la zona intermareal del conjunto de muelles es en promedio 40-50 m (Figura 8a), y el área sur luego del estuario del río Lacramarca, sin intervención antropogénica, es $35 \mathrm{~m}$ (Figura 8b), diferencia que explicaría retención de arena en el sector de muelles. También se puede observar que el extremo de varios muelles está en contacto con la arena en la franja supralitoral y, en algunos casos, en la banda intermareal, lo que interfiere en el flujo de arena por acción eólica. Adicionalmente, existen 4 muelles no operativos (Cuadro 2), que deberían ser retirados para reducir los impactos en el equilibrio sedimentario.

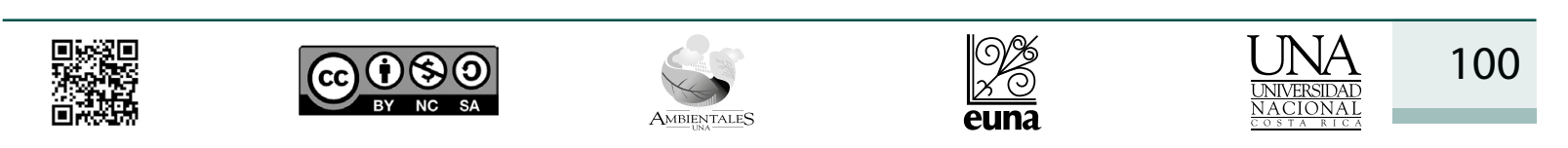




\section{Revista de CIENCIAS AMBIENTALES Tropical Journal of Environmental Sciences}

Revista de Ciencias Ambientales (Trop J Environ Sci) e-ISSN: 2215-3896 (Enero-Julio, 2021) . Vol 55(1): 86-117 DOI: https://doi.org/10.15359/rca.55-1.5

Open Access: www.revistas.una.ac.cr/ambientales e-mail: revista.ambientales@una.ac.cr Loayza-Aguilar R.

Cuadro 2. Muelles en desuso ubicados en la zona sur de la bahía El Ferrol, que deben ser retirados

Table 2. Disused docks located in the southern El Ferrol bay area, which must be removed

\begin{tabular}{|c|c|c|c|c|}
\hline \multirow{2}{*}{ Ubicación } & \multicolumn{3}{|c|}{ Dimensiones } & \multirow{2}{*}{ Descripción } \\
\hline & Largo (m) & Ancho (m) & Área (ha) & \\
\hline $\begin{array}{c}09^{\circ} 06^{\prime} 47^{\prime \prime} \mathrm{S} \\
78^{\circ} 33^{\prime} 47^{\prime \prime} \mathrm{W}\end{array}$ & 270 & 10 & 0.13 & $60 \mathrm{~m}$ en zona supralitoral. \\
\hline $\begin{array}{l}09^{\circ} 07^{\prime} 14^{\prime \prime} \mathrm{S} \\
78^{\circ} 33^{\prime} 40^{\prime \prime} \mathrm{W}\end{array}$ & 200 & 7 & 0.22 & $\begin{array}{l}390 \text { m de largo hasta su conexión con el astillero. Forma } \\
\text { de herradura en cabezo. }\end{array}$ \\
\hline $\begin{array}{l}09^{\circ} 07^{\prime} 18^{\prime \prime} \mathrm{S} \\
78^{\circ} 33^{\prime} 40^{\prime \prime} \mathrm{W}\end{array}$ & 180 & 9 & 0.13 & $\begin{array}{l}\text { Abandonado. A partir de } 80 \mathrm{~m} \text { en tierra retienen } \\
\text { importante volumen de arena. }\end{array}$ \\
\hline $\begin{array}{l}09^{\circ} 07^{\prime} 23^{\prime \prime} \mathrm{S} \\
78^{\circ} 33^{\prime} 39^{\prime \prime} \mathrm{W}\end{array}$ & 140 & 11 & 0.15 & $\begin{array}{l}\text { Abandonado. Retiene arena en toda su extensión. A } \\
\text { partir de } 93 \text { m está arenado. }\end{array}$ \\
\hline
\end{tabular}

La DHN (2003) y Ramos (2017) consideran que el principal aportante de sedimentos a la bahía es el río Lacramarca y, en menor proporción, por transporte eólico del istmo. En este contexto, si se pretende recuperar la dinámica sedimentaria de la bahía, facilitando el libre tránsito de arena, resulta pertinente: a) retirar los muelles en desuso (Cuadro 2), b) estudiar una altura adecuada para levantar el puente de los muelles que mantienen contacto con la zona supralitoral, para favorecer el tránsito eólico de la arena, c) restablecer la desembocadura del río Lacramarca a su posición de 2009, con el afán de mitigar la sedimentación en el lado sur y permitir que un mayor volumen de arena transite hacia el norte. Tomando en consideración que los eventos El Niño son cada vez más frecuentes e intensos (Figura 4), significará mayores aportes de arena a la bahía, que favorecerán el control de la erosión, pero también mayor sedimentación en el área de los muelles, de tal modo que es indispensable estudiar esta situación en el corto plazo.

\subsubsection{Infraestructura en línea litoral}

A fin de facilitar las operaciones en los muelles Gildemesiter y Pesquero Artesanal, se construyeron terrazas de concreto, de 70 y $140 \mathrm{~m}$ de ancho, respectivamente, que penetran $50 \mathrm{~m}$ en el mar (Figura 9a) y ocupan la zona intermareal y submareal. Pero, además, con el propósito de brindar servicios navales, adyacente a la terraza descrita, en 1959 inicia operaciones un astillero, de $130 \mathrm{~m}$ de largo, que penetra al mar $70 \mathrm{~m}$. En conjunto, todas estas estructuras ocupan 212 $\mathrm{m}$ de línea de playa y representan $70 \mathrm{~m}$ de espacio que se opone al transporte litoral de arena (Figura 9a), generando déficit sedentario en la playa La Caleta.

Algunas fábricas, molones de acceso a muelles, canales, tuberías, etc. fueron construidos en la zona supralitoral e intermareal (cfr.: Loayza, 1998, 2002b), y generan interferencia en el flujo de arena. Varias de estas estructuras han desaparecido y otras se mantienen desde fines de 1950 (Figura 9b, c). Actualmente, existe una edificación, con rocas amontonadas en el frontis, en la parte superior del intermareal en la zona de muelles (Figura 9d), que interfiere con el tránsito eólico de la arena hacia el norte. Toda la infraestructura que ha invadido el mar debe ser retirada en consideración a la Ley de Recursos Hídricos, 29338, y al Reglamento de la Ley de Control

\begin{tabular}{|c|c|c|c|c|c|}
\hline 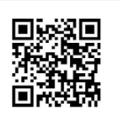 & (c) (1) (9) & $\Theta_{\text {AMBENATAIES }}$ & $\frac{10 \%}{20}$ & 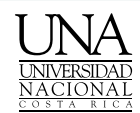 & 101 \\
\hline
\end{tabular}




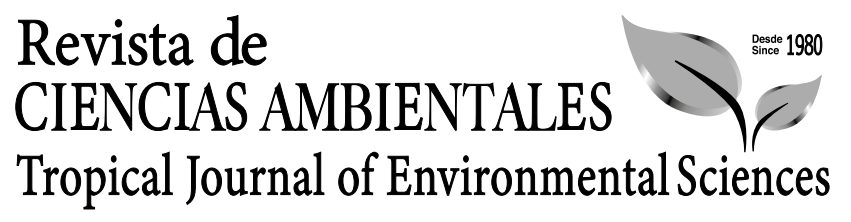

Revista de Ciencias Ambientales (Trop J Environ Sci) e-ISSN: $2215-3896$ (Enero-Julio, 2021) . Vol 55(1): 86-117 DOI: https://doi.org/10.15359/rca.55-1.5

Open Access: www.revistas.una.ac.cr/ambientales e-mail: revista.ambientales@una.ac.cr Loayza-Aguilar R.

y Vigilancia de las Actividades Marítimas, Fluviales y Lacustres (DS 028-2001-DE-MGP), para facilitar el tránsito de arena por acción eólica y litoral.

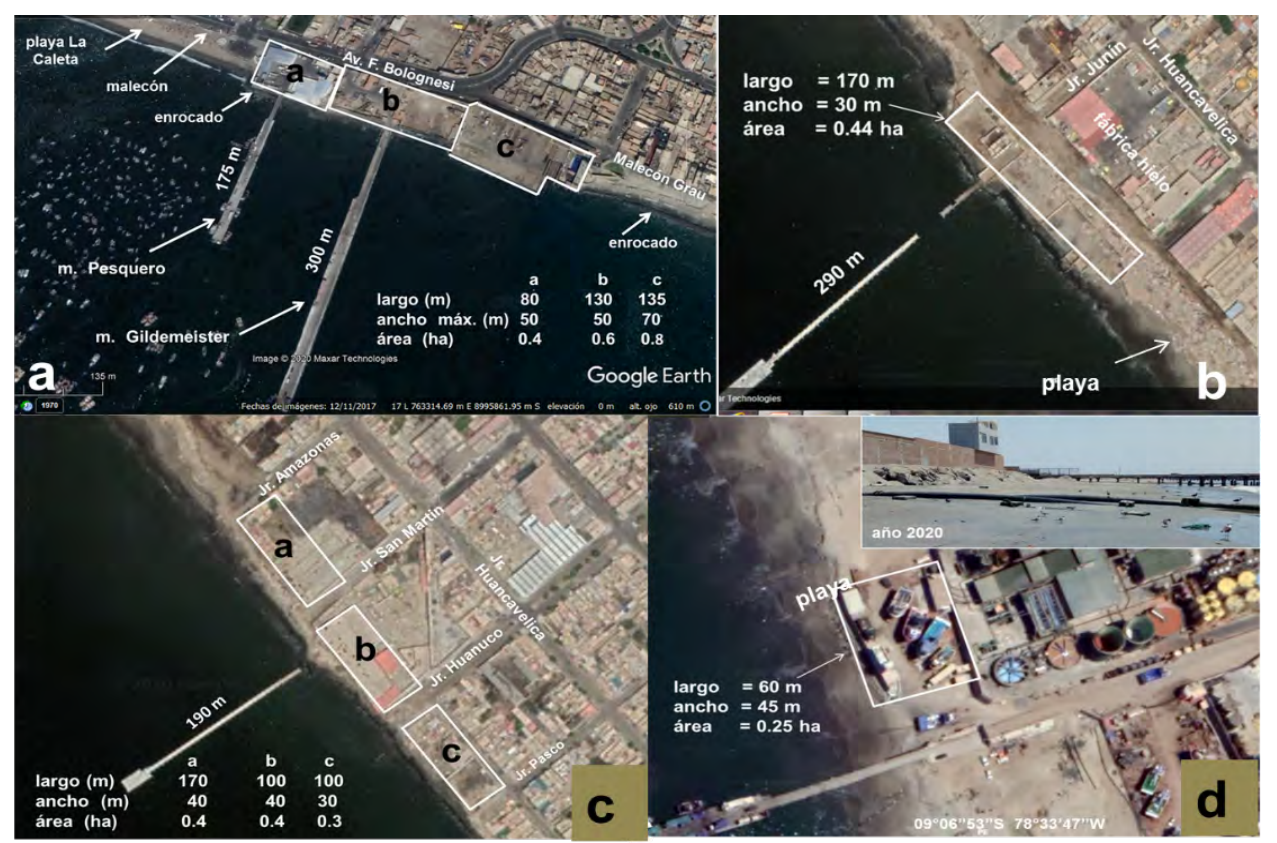

Figura 9. Presencia de terrazas, molones de acceso a muelles (a) y edificios (b y c) en zona norte, y edificios (d) en zona sur, sobre zona supralitoral e intermareal de la bahía El Ferrol (imágenes de Google Earth, octubre de 2019). Figure 9. Presence of terraces, cool access to docks (a) and buildings (b and c) in the north, and buildings (d) in the south, on the supralittoral and intertidal zone of El Ferrol bay (Google Earth images, October 2019).

Las estructuras sobresalientes construidas en la costa interfieren el flujo de arena por deriva marina, ya que alteran el campo de olas, cambian el flujo de sedimentos a lo largo de la costa y provocan, a menudo, erosión (Tsoukala et al., 2015). Cuando las olas se propagan en un medio sin obstáculos, mantienen uniformidad en su altura; sin embargo, ante uno, como la infraestructura encontrada en la zona intermareal y submareal de la bahía (Figura 9), en el dominio de propagación del oleaje se genera una zona de sombra (Figura 10). Esto último ocasiona mayores gradientes de altura en el frente de la ola, lo que induce una transferencia lateral de energía que puede graficarse en el oleaje interrumpido por la estructura, cortando la energía de este (DHN, 2013; Ramos, 2017) y produciendo erosión. Debido al ancho de las estructuras sobresalientes (Figura 9), se debe sumar el efecto de turbulencia presente cuando la energía de las olas, al romper sobre esas estructuras, se transforma en turbulenta (Figura 10) y acrecienta la erosión.

\begin{tabular}{|c|c|c|c|c|c|}
\hline 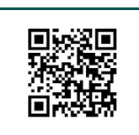 & (c) (1) () (2) & 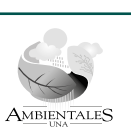 & 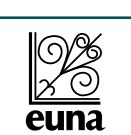 & 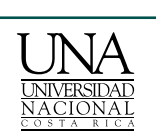 & 102 \\
\hline
\end{tabular}




\section{Revista de CIENCIAS AMBIENTALES Tropical Journal of Environmental Sciences}

Revista de Ciencias Ambientales (Trop J Environ Sci) e-ISSN: 2215-3896

(Enero-Julio, 2021) . Vol 55(1): 86-117 DOI: https://doi.org/10.15359/rca.55-1.5

Open Access: www.revistas.una.ac.cr/ambientales e-mail: revista.ambientales@una.ac.cr Loayza-Aguilar R.

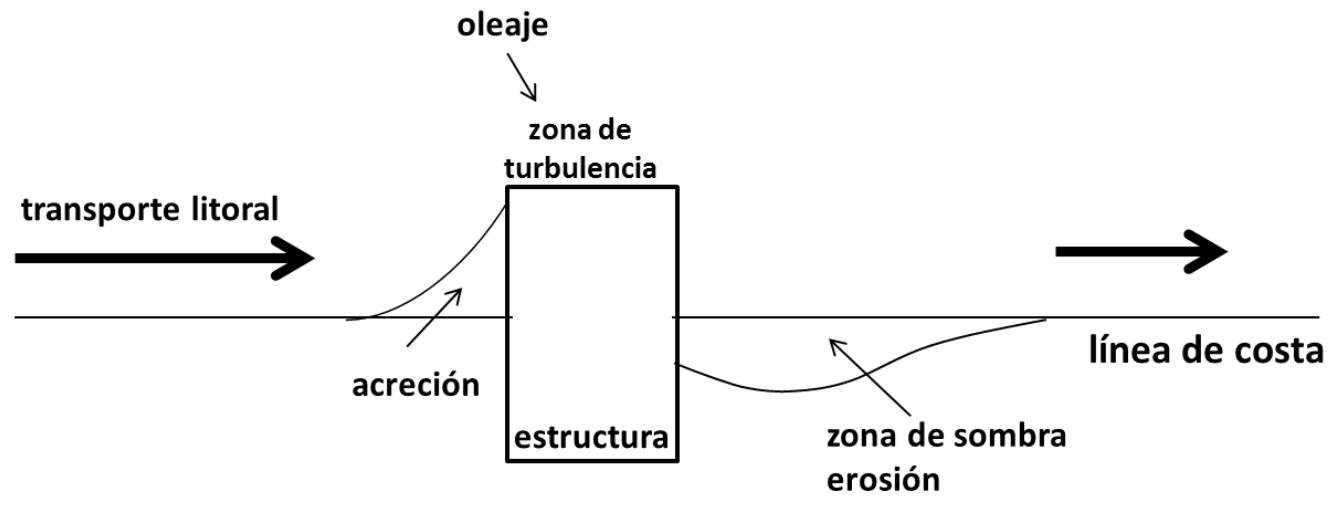

Figura 10. Representación de la línea de costa modificada por acción de estructuras en zonas intermareal y submareal de la bahía El Ferrol.

Figure 10. Representation of the coastline modified by the action of structures in the intertidal and subtidal zones of El Ferrol bay.

\subsubsection{Enrocado}

La primera respuesta ante erosión en la bahía fue enrocar la línea costera frente al casco urbano (1976-1977) y, en la línea de erosión no enrocada, disponer desmonte, no cuantificado, pero que en la práctica se tendrá que estimar con fines de gestionar la playa. A mediados de la década de 1990, se colocan rocas en la línea de erosión no enrocada y, en el 2004, se construye un enrocado para reemplazar al antiguo, entre el Jr. G. Moore y el Jr. Tumbes; progresivamente, se hacen enrocados, entre clásico ( $3 \mathrm{~m}$ de ancho) y rústico, hasta el Jr. 28 de Julio (barrio La Libertad).

No obstante que el oleaje en la bahía es pequeño, en otoño e invierno, los vientos incrementan su velocidad (Ramos, 2010); entre el hotel y el barrio Miramar, llegan olas más altas y con mayor celeridad, así como el run-up es superior a la cota de coronación del enrocado, hecho que produce inundación de la zona urbana, perjudicando el pavimento, veredas y actividades rutinarias. Para mitigar estos efectos, se ha realizado algunas adecuaciones (Figura 11): a) en el 2012, al sur de la plaza 28 de Julio, se ha construido, a $15 \mathrm{~m}$ del enrocado, un rompeolas tipo pirámide trunca, de $3 \times 10 \mathrm{~m}$ en la base trunca y $5 \mathrm{~m}$ de altura; b) entre el sur de la plaza 28 de Julio y el Jr. Tumbes, se ha erigido una sobrecorona al enrocado, de $1.10 \mathrm{~m}$ de altura, y c) en el 2019, en el frente de la plaza 28 de Julio, se levantó un rompeolas en la base del mismo enrocado, a $5.5 \mathrm{~m}$ de la corona del enrocado y de $2.0 \mathrm{~m}$ de altura.

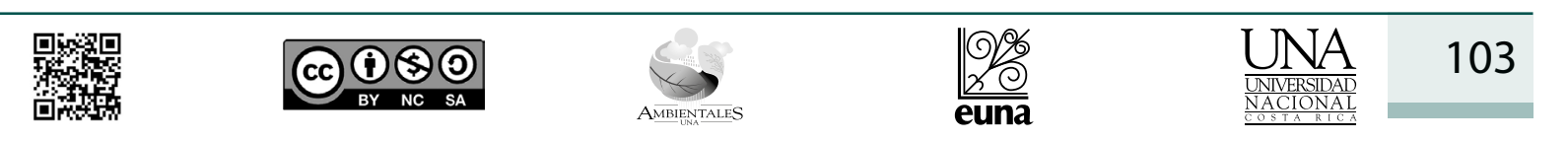




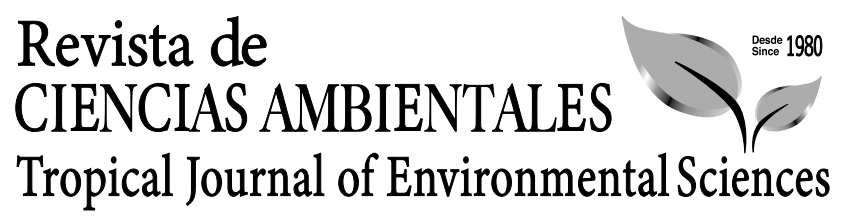

Revista de Ciencias Ambientales (Trop J Environ Sci) e-ISSN: 2215-3896 (Enero-Julio, 2021) . Vol 55(1): 86-117 DOI: https://doi.org/10.15359/rca.55-1.5 Open Access: www.revistas.una.ac.cr/ambientales e-mail: revista.ambientales@una.ac.cr Loayza-Aguilar R.

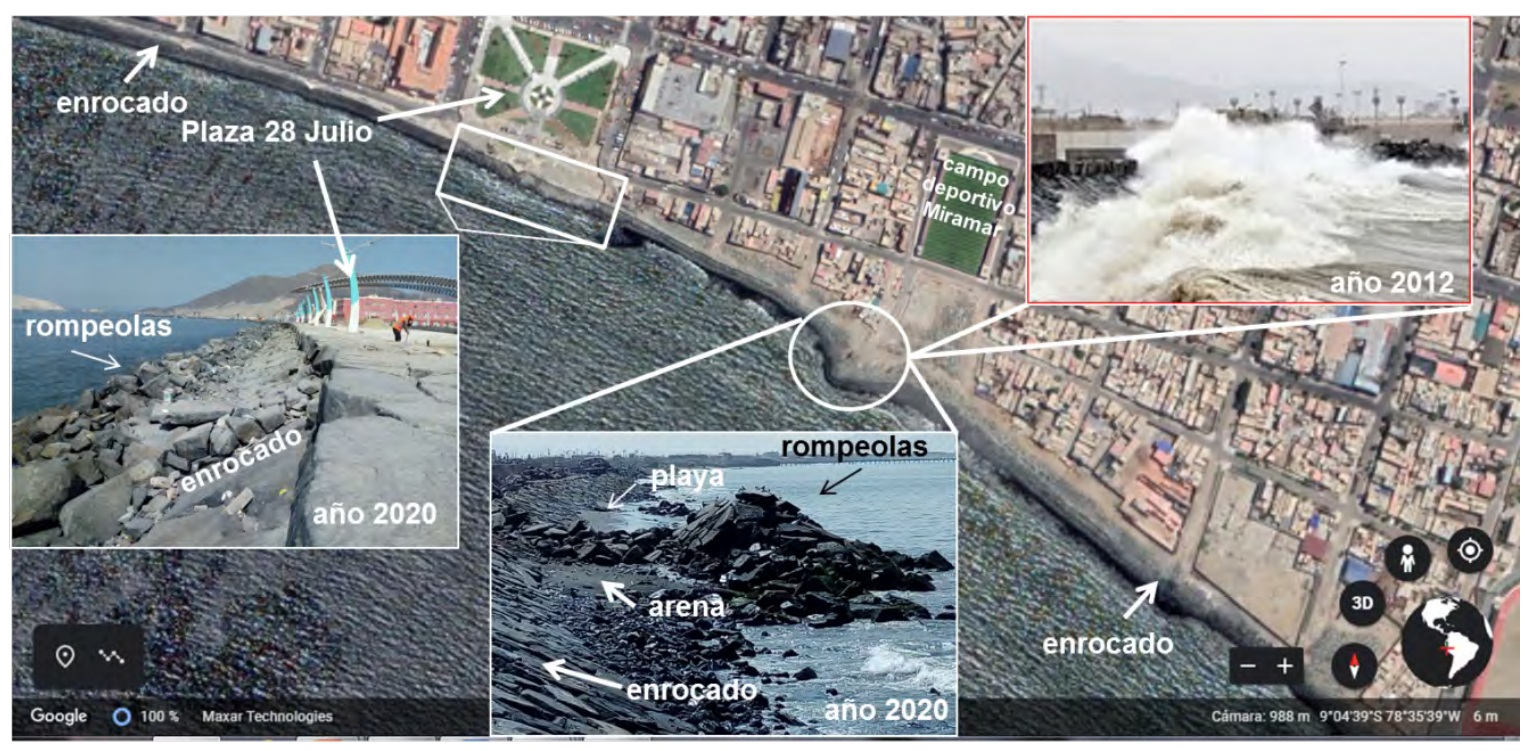

Figura 11. Presencia de terrazas (a), molones de acceso a muelles y edificios (b y c) en zona norte, y edificios (d) en zona intermareal de la bahía El Ferrol (imagen de fondo de Google Earth, octubre de 2019, fotos de enero de 2020).

Figure 11. Presence of terraces (a), dock access structures, and buildings (b and c) in the north, and buildings (d) in the intertidal zone of El Ferrol bay (Google Earth background image, October 2019, photos January 2020).

El rompeolas de base trunca mitiga bien el efecto del oleaje anómalo, ha formado un tómbolo y propicia el restablecimiento de una playa al sur de este (Figura 11). El enrocado entre el Jr. G. Moore y la plaza 28 de Julio, luego de unos 3 años de operación, comenzó a mostrar que se separa de las rocas en la corona del enrocado y algunas se deslizaron al mar. Rangel-Buitrago y Posada-Posada (2013) señalan que la ciudad de Cartagena (Colombia) se encuentra protegida para defenderse de la erosión, pero es ineficiente y desencadena ese fenómeno en sus inmediaciones. En general, los enrocados son temporales, no resuelven la erosión, afectan la naturalidad de las playas, favorecen la aparición de otros procesos erosivos y la intensificación de los ya existentes (Williams et al., 2017). Las olas, al acercarse a la línea de orilla, se ven afectadas por el fondo, lo cual promueve que su altura crezca hasta desestabilizarse y perder su forma; de tal modo, la velocidad de la onda, en la parte superior de la cresta, supera la celeridad de la ola y las partículas escapan de la cresta, se lanzan hacia delante y producen la rotura de la onda (Ramos, 2017). Cuando esta rotura ocurre delante, el chorro de agua lanzado desde la cresta de la ola penetra en la base de la onda, atrapa aire en el túnel, provoca una gran turbulencia (Rodríguez y Beltrán, 2012) y el material erosionado se mueve en la dirección de la pendiente, a las partes más bajas; sin embargo, cuando existe un enrocado, la turbulencia es mayor, se puede generar mayor erosión junto a la cara del enrocado hacia el lado del mar (Suárez, 2001), causa de su desestabilización.

\begin{tabular}{|c|c|c|}
\hline 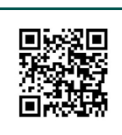 & (c) (1) (3) (2) & 104 \\
\hline
\end{tabular}




\section{Revista de CIENCIAS AMBIENTALES Tropical Journal of Environmental Sciences}

Revista de Ciencias Ambientales (Trop J Environ Sci) e-ISSN: 2215-3896 (Enero-Julio, 2021) . Vol 55(1): 86-117 DOI: https://doi.org/10.15359/rca.55-1.5

Open Access: www.revistas.una.ac.cr/ambientales e-mail: revista.ambientales@una.ac.cr Loayza-Aguilar R.

Mantener protegida la ciudad del proceso erosivo en la bahía, a través de enrocados implica: a) alta inversión para enrocar el litoral hasta el 27 de Octubre, mantenimiento del enrocado por desestabilización, cambios de este, por desestabilización crítica, construcción de rompeolas en zonas críticas e incremento de los impactos negativos del spray marino; b) en el mediano plazo, por incremento del nmm, que el proceso erosivo sea más intenso y el enrocado tenga una menor vida útil (Williams et al., 2017); c) no reconocer la aspiración de la comunidad por recuperar las cualidades naturales de la bahía, con implicancias económicas, sociales y culturales. Lo ideal es restablecer el equilibrio sedimentario natural, ya que resulta más seguro y menos costoso.

En resumen, luego del diagnóstico y el análisis de los factores que contribuyen con el proceso erosivo en la bahía, con base en una ponderación subjetiva, en el Cuadro 3 se presenta una jerarquización de los aspectos más importantes, que en su momento contribuyan en el establecimiento de planes para la recuperación de la línea costera.

Cuadro 3. Factores generadores de erosión en la bahía El Ferrol y grado de ponderación

Table 3. Factors generating erosion in El Ferrol bay and degree of weighting

\begin{tabular}{l|l|c}
\hline \multicolumn{1}{c}{ Factor perturbador } & \multicolumn{1}{c}{ Impacto } & \multicolumn{1}{c}{$\begin{array}{c}\text { Ponderación } \\
(\mathbf{1}-\mathbf{1 0})\end{array}$} \\
\hline Materia orgánica & $\begin{array}{l}\text { Atrapa arena, limita transporte litoral. } \\
\text { Ubicados en extremo norte, generan acreción, escasa interferencia } \\
\text { con zona erosionada. }\end{array}$ & 2 \\
Espigones & $\begin{array}{l}\text { Área de ubicación retiene arena, limitando transporte litoral. } \\
\text { Interfiere el transporte litoral y el eólico. } \\
\text { Promueve erosión, impidiendo acumulación de arena y } \\
\text { desestabilización de rocas. } \\
\text { Duelles 27 de Octubre } \\
\text { Infraestructura litoral } \\
\text { Enrocado }\end{array}$ & 4 \\
Ubicación de río & el transporte de arena hacia sector erosionado. & 10 \\
\hline
\end{tabular}

1 = escaso impacto, 10 = máximo impacto.

\subsection{Capacidad resiliente de la bahía}

Todos los sistemas naturales tienen capacidad para recuperarse de un impacto, conocida como resiliencia (Klein y Nicholls, 1999). La resiliencia costera es la facultad de la costa para adaptarse a cambios provocados por la elevación del $\mathrm{nmm}$, fenómenos climáticos extremos e impactos humanos, conservando sus funciones naturales. Con el fin de determinar la capacidad resiliente del litoral marino, se manejan dos criterios: a) la disponibilidad suficiente de sedimentos para mantener el equilibrio dinámico entre erosión y sedimentación; b) el espacio necesario para la actuación de los procesos costeros (Comisión Europea, 2005). Lo anterior, en tanto las playas están constituidas por un sistema marino controlado por el viento, oleaje y las mareas, y el ecosistema terrestre, manejado por el viento y la lluvia, así como que ambos sistemas interactúan en unidad geomorfológica (cfr.: Prasad y Kumar, 2014). Para revertir el proceso erosivo en la bahía, lo prioritario es restablecer el equilibrio sedimentario; la condición básica es

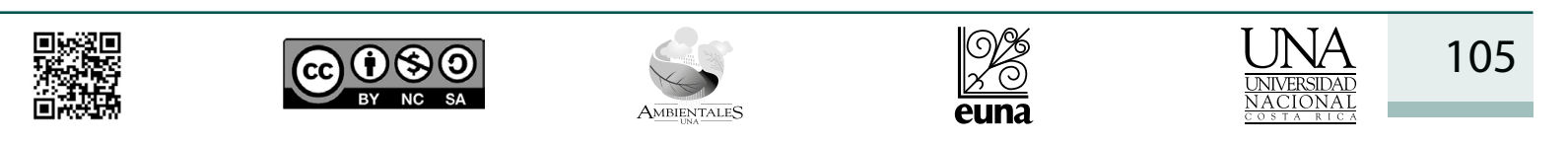




\section{Revista de CIENCIAS AMBIENTALES Tropical Journal of Environmental Sciences}

Revista de Ciencias Ambientales (Trop J Environ Sci) e-ISSN: 2215-3896 (Enero-Julio, 2021) . Vol 55(1): 86-117 DOI: https://doi.org/10.15359/rca.55-1.5

Open Access: www.revistas.una.ac.cr/ambientales e-mail: revista.ambientales@una.ac.cr Loayza-Aguilar R.

el retiro de la infraestructura abandonada, que interfiere en el transporte litoral de arena, pero, a su vez, se precisa conocer con profundidad la dinámica sedimentaria del sistema dunar y del río Lacramarca.

\subsubsection{Sistema dunar}

Las dunas costeras son sistemas frágiles, generados por la acumulación de arena debida a la acción eólica, que protegen contra la erosión, pero amenazados por factores naturales (suministro de arena, tasa de transporte, fuerzas del viento, ocurrencia de tormentas, humedad y vegetación) y humanos (turismo masivo, construcción de paseos, carreteras, instalación de servicios) (Roig-Munar et al., 2018). El sistema dunar hasta 1972, cuando se traslada la desembocadura del río Lacramarca al sur de la bahía, era la única fuente de abastecimiento de arena para esta; sin embargo, en el presente, la DHN (2019), utilizando modelos numéricos, estima que el río Lacramarca aporta $9000 \mathrm{~m}^{3}$ año ${ }^{-1}$ de sedimento y unos $2000 \mathrm{~m}^{3}$ año ${ }^{-1}$ por aporte eólico del istmo.

Desde mediados de 2000, el campo de dunas del istmo (Figura 2), coincidente con la ampliación de las lagunas de oxidación Las Gaviotas en el humedal de Villa María, ha elevado el nivel freático, de tal modo que hacia el lado sureste han aparecido charcos, bañados, pequeñas lagunas, suelo con sales cristalizadas y plantas pioneras como Distichlis spicata, Sesuvium portulacstrum y Salicornia fructicosa (Figura 12). Producto del afloramiento, la pista de aterrizaje del Aeropuerto de Chimbote se encuentra inundada (Figura 12) y muchas dunas se humedecen y desaparecen. Las partes noroeste y suroeste aún mantienen la formación y el traslado de dunas (Figura 12), mientras la fuente de arena a la bahía es por acción eólica.

\begin{tabular}{|c|c|c|}
\hline 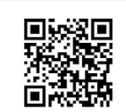 & (c) () (9) & 106 \\
\hline
\end{tabular}




\section{Revista de CIENCIAS AMBIENTALES Tropical Journal of Environmental Sciences}

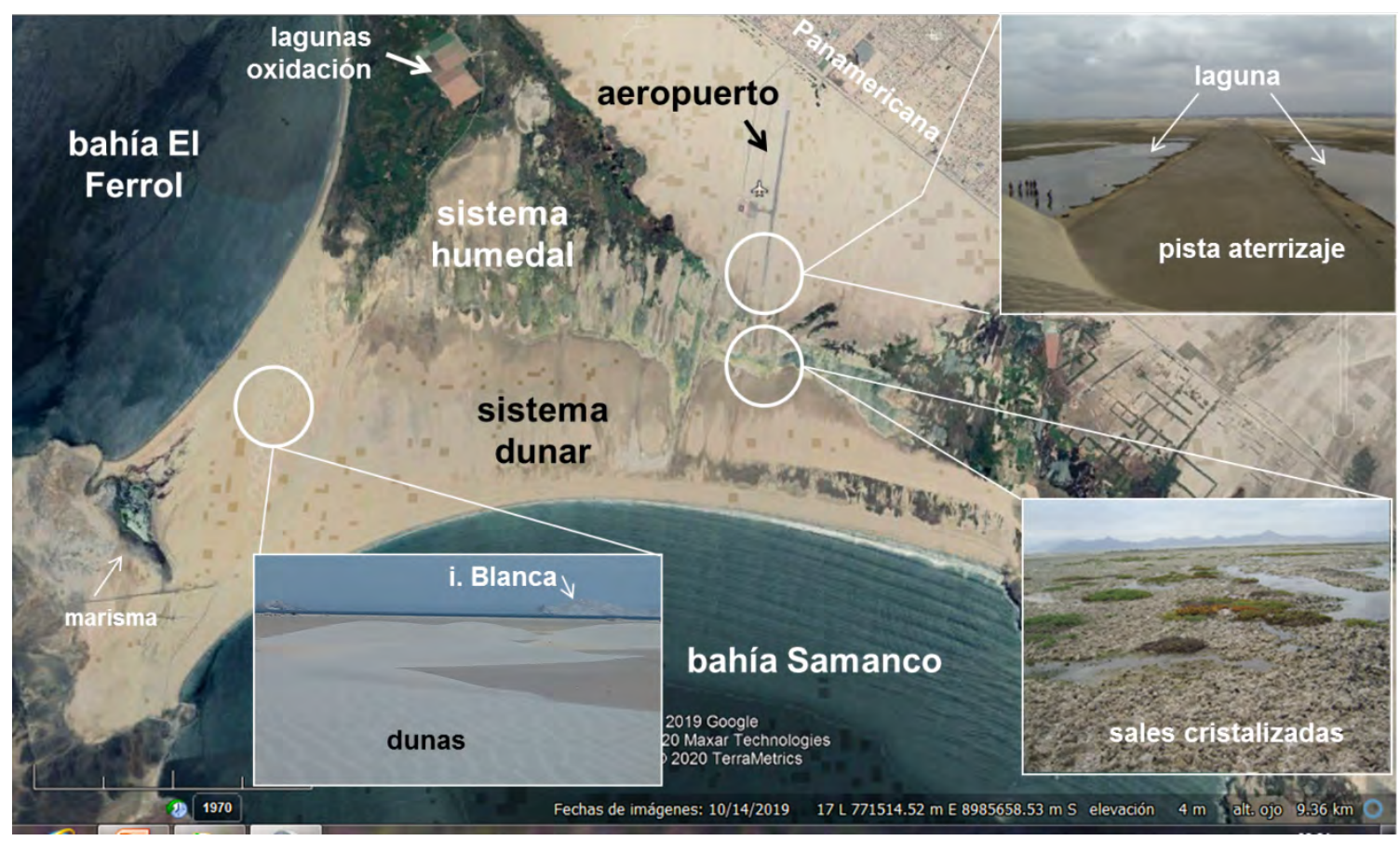

Figura 12. Situación del sistema dunar en el istmo que separa la bahía El Ferrol y la bahía de Samanco (imagen de Google Earth, octubre de 2019).

Figure 12. Situation of the dune system in the isthmus that separates El Ferrol Bay and Samanco Bay (Google Earth image, October 2019).

El afloramiento de agua y suelo húmedo tienen efecto aglomerante de las partículas de arena, elevan la velocidad umbral para movilizarlas, por lo que se estima que un incremento de 0.6 $\%$ en el volumen de humedad puede duplicar o incluso triplicar el valor de la velocidad umbral de arrastre y, si la humedad crece hasta en $2 \%$, cesa el transporte, incluso a velocidades de 25 $\mathrm{m} \mathrm{s}^{-1}$. Además, las sales cristalizadas y la vegetación incrementan la rugosidad del sustrato, con repercusiones sobre el valor crítico del despegue (cfr.: Sanjaume et al., 2011). La conversión progresiva del sistema dunar a humedal genera más incertidumbre como fuente de arena para la bahía.

El acelerado desarrollo industrial en Chimbote ocasionó la ocupación de la línea de orilla de la bahía: la zona centro por el parque industrial pesquero y la norte (Figura 1) por la urbanización de la ciudad, reduciendo la franja de circulación eólica de la arena a la bahía (Figura 2). A fines de 1990, se construyó una trocha de este a oeste en el istmo y en el 2020 se han iniciado trabajos para asfaltar esa trocha. El ancho de la playa de Cancún (México), entre 1970 y 1999, se redujo de 70.95 a $16.26 \mathrm{~m}$, por construcción de hoteles y vías, con invasión de la duna y las playas (Guido et al., 2009). Esto demuestra que las dunas y las playas, al igual que su interacción,

\begin{tabular}{|c|c|c|}
\hline 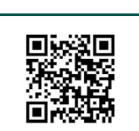 & (c) (1) () (2) & $\overline{107}$ \\
\hline
\end{tabular}




\section{Revista de CIENCIAS AMBIENTALES Tropical Journal of Environmental Sciences}

Revista de Ciencias Ambientales (Trop J Environ Sci) e-ISSN: 2215-3896 (Enero-Julio, 2021) . Vol 55(1): 86-117 DOI: https://doi.org/10.15359/rca.55-1.5

Open Access: www.revistas.una.ac.cr/ambientales e-mail: revista.ambientales@una.ac.cr Loayza-Aguilar R.

son muy frágiles, pueden llegar a perder su capacidad resiliente por acción humana; de allí la necesidad de emprender estudios para conocer la dinámica dunar.

\subsubsection{Río Lacramarca}

Desde 1972, el caudal de este río se mantiene entre $2.5 \mathrm{y}_{4} \mathrm{~m}^{3} \mathrm{~s}^{-1}$, incorpora sedimento al sur de la bahía. Este caudal se incrementa durante eventos El Niño, como entre 1997-98, cuando llegó de 180 a $280 \mathrm{~m}^{3} \mathrm{~s}^{-1}$ (Cuenca y Desarrollo, 1998).

En 1972, cuando la desembocadura del río Lacramarca fue trasladada al sur de la bahía, descargaba a unos $450 \mathrm{~m}$ al sur del muelle SIMA-Chimbote (DHN, 2009), pero originaba sedimentación, lo cual reducía la capacidad física de dicho muelle, que en 1979 tenía extensión útil de $300 \mathrm{~m}$ y, en el 2000, de $180 \mathrm{~m}$ (Figuras 13a, b) (Ramos, 2017). Esto obligaba permanentes operaciones de dragado para facilitar el tránsito de las embarcaciones (MINAM, 2012) y en el 2009 la desembocadura del río fue trasladada por el SIMA-Chimbote a más de $1000 \mathrm{~m}$ hacia el sur (Figura 13c).

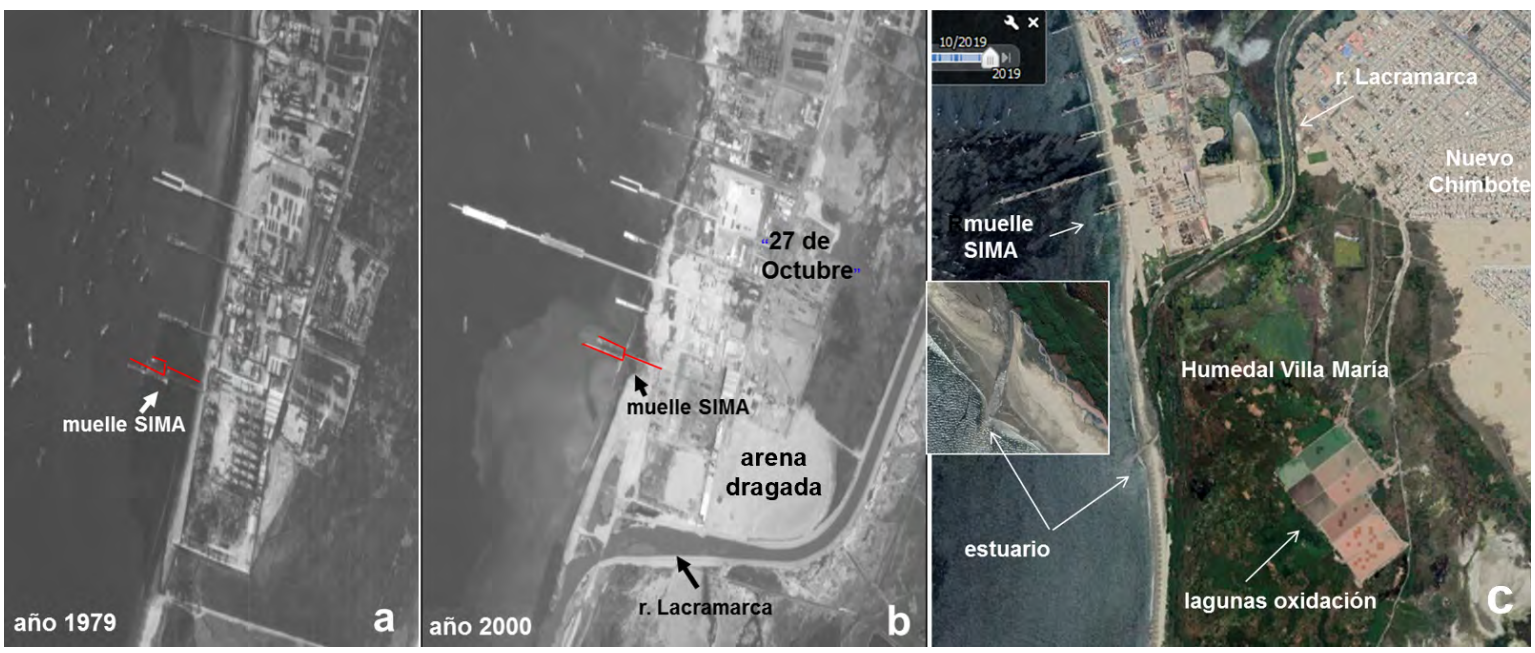

Figura 13. Variación de la desembocadura (estuario) del río Lacramarca al sur de la bahía El Ferrol (imágenes de la DHN, 2000; Google Earth, octubre de 2019)

Figure 13. Variation of the mouth (estuary) of the Lacramarca river south of El Ferrol bay (DHN, 2000 and Google Earth, October 2019 images).

La zona más meridional de la bahía, donde descarga el río Lacramarca, es la menos profunda y más calma, ya que está protegida por el cerro Península y las islas Ferrol, por tanto, el transporte litoral de arena hacia el norte es restringido, promoviendo acumulación de esta en el sur. Ramos (2017) señala que, entre 2003-17, en esta área ha ocurrido una variación de la línea de orilla de $25 \mathrm{~m}$, debida a sedimentación, a una tasa de $1.9 \mathrm{~m}$ año $^{-1}$. En este contexto, resulta

\begin{tabular}{|c|c|c|}
\hline 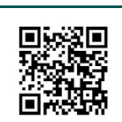 & (c) (i) () (2) & 108 \\
\hline
\end{tabular}




\section{Revista de CIENCIAS AMBIENTALES Tropical Journal of Environmental Sciences}

Revista de Ciencias Ambientales (Trop J Environ Sci) e-ISSN: 2215-3896 (Enero-Julio, 2021) . Vol 55(1): 86-117 DOI: https://doi.org/10.15359/rca.55-1.5 Open Access: www.revistas.una.ac.cr/ambientales e-mail: revista.ambientales@una.ac.cr Loayza-Aguilar R.

coherente restablecer la desembocadura el río a su posición de 2009, para mitigar la sedimentación al sur de la bahía y facilitar el tránsito de la arena hacia el norte, como zona deficitaria.

\subsection{Signos de recuperación del litoral erosionado}

Dos hechos importantes: a partir de 2015, las fábricas dejaron de disponer efluentes a la bahía y, por tanto, lodos, lo que redujo la retención de arena; por otro lado, los aportes de arena a la bahía durante El Niño Costero 2017 (DHN, 2019) influyeron en el predominio de arena en el fondo. Probablemente, producto de estos aspectos, actualmente en marea baja se puede apreciar la formación de playas en la base del enrocado, desde el Jr. G. Moore. Esto se evidencia más hacia el sur, donde se distingue zona intermareal mayor de $30 \mathrm{~m}$ y otra supralitoral de más de $10 \mathrm{~m}$, que mantiene el frente con desmonte, colocado algunos años atrás (Figura 14).

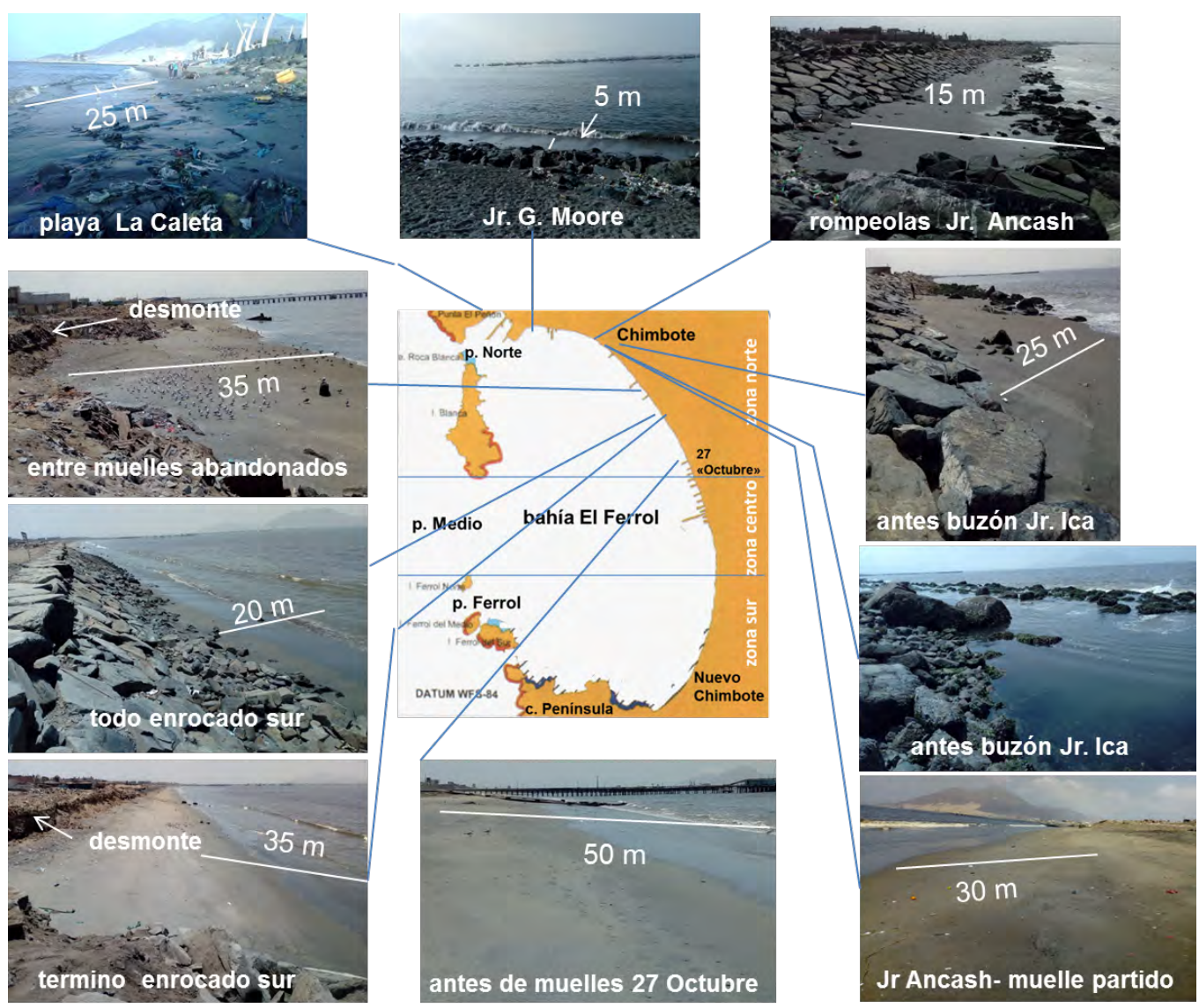

Figura 14. Presencia de playas a lo largo del litoral erosionado de la bahía El Ferrol, registradas en enero-febrero de 2020, en condiciones de marea baja.

Figure 14. Presence of beaches along the eroded coastline of El Ferrol bay, recorded in January-February 2020, under low tide conditions.

\begin{tabular}{|c|c|c|}
\hline 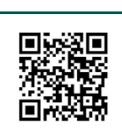 & (c) (i) () (1) & 109 \\
\hline
\end{tabular}




\section{Revista de CIENCIAS AMBIENTALES Tropical Journal of Environmental Sciences}

Revista de Ciencias Ambientales (Trop J Environ Sci) e-ISSN: 2215-3896 (Enero-Julio, 2021) . Vol 55(1): 86-117 DOI: https://doi.org/10.15359/rca.55-1.5

Open Access: www.revistas.una.ac.cr/ambientales e-mail: revista.ambientales@una.ac.cr

Loayza-Aguilar R.

\subsection{Avances técnico-financieros para resolver el proceso erosivo}

La gestión de playas debe basarse en el conocimiento de los procesos de erosión, sin embargo, en un alto porcentaje de decisiones, prima el criterio económico (Williams et al., 2017), aplicable al caso de la bahía El Ferrol, donde no existe un plan de gestión, que contemple un cronograma de actividades y fuentes de financiamiento. Las emergencias de enrocado son resueltas con finanzas del gobierno local o regional. Es importante considerar que, para resolver el problema erosivo en la bahía, se requiere un enfoque integral de su problemática, largo plazo y un programa con recursos monetarios seguros que garanticen la implementación de actividades previstas.

\subsection{Escenarios sugeridos para el modelo numérico de erosión}

Los estudios realizados sobre el proceso erosivo de la bahía son insuficientes para emprender medidas orientadas a restablecer la subsistencia integral del sistema, aun cuando existen algunos elementos que no requieren mayores detalles, porque son condicionantes para la recuperación, como a) retiro de infraestructura innecesaria del litoral, mucha en estado de abandono (CTM, 2012) (Figura 9), y evaluar la operativa, teniendo como propósito que el resultado de la dinámica sedimentaria sea positivo; b) restablecimiento de la desembocadura del río Lacramarca a su posición del momento en que fue trasladado al sur de la bahía ( $450 \mathrm{~m}$ al sur del SIMA-Chimbote), para facilitar mayor flujo de arena hacia la zona que sufre erosión. Con el propósito de valorar medidas como relleno previo con arena, rompeolas sumergidos, rompeolas flotantes, etc. (Tsoukala et al., 2015), es indispensable aplicar modelos numéricos adecuados para formaciones arenosas (Ojeda, 2000), herramienta eficaz para reproducir las características de la dinámica marina y costera, mediante la definición de escenarios que permitan estudiar, en forma aislada, la influencia de cada una de las variables involucradas (Guzmán, 2006b).

Basándose en modelos numéricos de la dinámica de la bahía, la DHN (2008) señala que la recuperación no podría darse de forma natural, debido a bajas tasas de transporte de sedimentos; complementa, luego (DHN, 2019), que el relleno de las playas del norte es el mejor panorama para su recuperación. Tomando en cuenta estos avances, se considera pertinente ensayar los siguientes escenarios:

a) Dinámica del sistema dunar: a1) semejando las condiciones naturales de la bahía (Figuras 1 y 2), sin los espigones y el molón, ni aportes del río Lacramarca, ubicado hasta 1972 al norte; a2) bajo las condiciones actuales, con incremento de la napa freática en la zona dunar, que interfiere con la acumulación y el transporte de arena, lo cual permita definir, cuantitativamente, el aporte sedimentario.

b) Influencia de espigones y molón: b1) como eventuales desencadenantes del proceso erosivo en la bahía, al incrementar el nmm por oposición a la corriente; b2) sus efectos en la dirección de las corrientes en el extremo norte y dinámica sedimentaria.

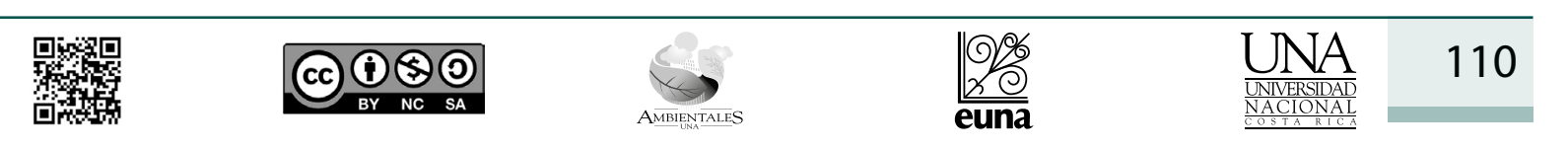




\section{Revista de CIENCIAS AMBIENTALES Tropical Journal of Environmental Sciences}

Revista de Ciencias Ambientales (Trop J Environ Sci) e-ISSN: 2215-3896 (Enero-Julio, 2021) . Vol 55(1): 86-117 DOI: https://doi.org/10.15359/rca.55-1.5

Open Access: www.revistas.una.ac.cr/ambientales e-mail: revista.ambientales@una.ac.cr Loayza-Aguilar R.

c) Ocupación de la zona intermareal por infraestructura, como molones de acceso a muelles, terrazas de operaciones industriales, etc., para cuantificar su oposición al tránsito litoral de arena por acción eólica y deriva litoral.

d) Acumulación de lodos en el lado sur de la bahía, para cuantificar su efecto aglomerante y su capacidad de atrapamiento de arena que transita de sur a norte.

e) Retención de arena en la zona de muelles en el 27 de Octubre: e1) en condiciones actuales, sin la presencia de muelles; e2) en condiciones actuales, con la presencia de muelles, que inste proponer medidas adecuadas a la realidad.

f) Aportes del río Lacramarca: f1) en su posición, cuando fue cambiado el cauce al sur de la bahía; f2) en los puntos al sur, debido al desvío que genera el SIMA-Chimbote (Figura 13c), lo cual promueva determinar la posición real de la desembocadura en función del mayor flujo de arena hacia la zona de erosión.

g) El comportamiento del enrocado en las condiciones actuales, para establecer el grado de estabilidad de la estructura y pronosticar la frecuencia tanto de su mantenimiento como de su eventual cambio.

h) El incremento del nmm, relacionado con el calentamiento global, ya que constituye una variable insustituible por tener en cuenta en estos propósitos.

\section{Conclusiones}

La bahía El Ferrol enfrenta un proceso erosivo desde mediados de 1970, generado por acción humana. Perdió sus playas entre 60 y 100 m de amplitud en 6200 m (45\%) de su litoral norte-centro, de los cuales $50 \%$ cuenta con enrocado clásico, $27 \%$ con piedras amontonadas, $13 \%$ con desmonte y $10 \%$ sin protección; en tanto, la zona sur sufre un proceso de sedimentación. El espacio de mayor erosión está entre la plaza 28 de Julio y el barrio Miramar, donde el enrocado cuenta con rompeolas, para mitigar la inundación urbana y desestabilización de las rocas. Las principales fuentes de abastecimiento de arena a la bahía son: a) el río Lacramarca, que contribuye con $9000 \mathrm{~m}^{3} \mathrm{año}^{-1}$, y b) el sistema dunar localizado en el istmo, con aportación eólica de $2000 \mathrm{~m}^{3}$ año-1 no obstante, por incremento inducido del nivel freático, está disminuyendo sus aportes.

A la luz de lo investigado y las observaciones in situ, las principales causas del proceso erosivo en la bahía, en orden de importancia son: a) las construcciones en la zona supralitoral, intermareal y hasta submareal (molones de acceso a muelles, terrazas para operaciones pesqueras e industriales, almacenes, tuberías, muelles en contacto con la zona supralitoral), que interfieren en el transporte litoral de arena; b) el traslado del río Lacramarca hacia el sur de la bahía en 1972, que contribuye con el abastecimiento de arena, pero la extensión forzada de su

\begin{tabular}{|c|c|c|c|c|c|}
\hline 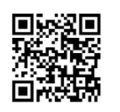 & (c) $\underset{\mathrm{BY}}{(1)}(0)$ & $\underset{\text { AMBENETILES }}{3}$ & $\begin{array}{l}\frac{O O}{2} \\
\frac{2}{2} \\
\text { euna }\end{array}$ & 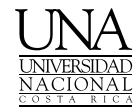 & 111 \\
\hline
\end{tabular}




\section{Revista de CIENCIAS AMBIENTALES Tropical Journal of Environmental Sciences}

Revista de Ciencias Ambientales (Trop J Environ Sci) e-ISSN: 2215-3896 (Enero-Julio, 2021) . Vol 55(1): 86-117 DOI: https://doi.org/10.15359/rca.55-1.5

Open Access: www.revistas.una.ac.cr/ambientales e-mail: revista.ambientales@una.ac.cr Loayza-Aguilar R.

desembocadura en el 2009, por más de $1000 \mathrm{~m}$ al sur, ocasiona que esa arena se disponga en una zona calma y produce tanto sedimentación en el sur como limitaciones para el transporte litoral de dicho elemento hacia la zona de erosión; c) el enrocado, una estructura que no permite la recuperación de playa por los problemas de la dinámica energética de las olas.

La retención de arena por los lodos en la zona centro de la bahía estaría siendo mitigada por dos razones: por un lado, desde el 2015 las fábricas pesqueras no disponen efluentes orgánicos a la bahía; por otro, el aporte de arena durante El Niño costero 2017 permite mayor predominancia de esta. La retención de arena en el área del 27 de Octubre donde se concentran los muelles requiere ser estudiada, para establecer la relación causa-efecto entre estos y sedimentación. Los eventos El Niño, en cuanto son temporales, no se presentan como factor de erosión.

En atención a lo observado y las ocurrencias en el mundo, el enrocado es una solución temporal al efecto erosivo y, de no aplicar alguna tecnología para recuperar el equilibrio sedimentario, en el largo plazo significará una carga económica importante para el gobierno local, al igual que una barrera para recuperar las condiciones naturales de la bahía. Es indispensable retirar toda la infraestructura portuaria que interfiere con el transporte eólico y por deriva litoral de arena, en aplicación de la Ley de Recursos Hídricos y el Reglamento de la Ley 26620 (Ley de Control y Vigilancia de las Actividades Marítimas, Fluviales y Lacustres), básicos en la implementación de estrategias para recuperar y estabilizar el equilibrio sedimentario.

Se plantea una serie de escenarios de modelación numérica, cuyos resultados permitan formular un plan de largo plazo para gestionar la bahía, incluido el factor de incremento del $\mathrm{nmm}$ por el calentamiento global. También, y para gestionar la bahía, es razonable la creación de una institución autónoma, que administre fuentes de financiamiento para la obtención de datos continuos de largo plazo, los cuales faciliten y efectivicen la aplicación de modelos numéricos que limiten la incertidumbre en la fiabilidad de los diseños de obras, así como su correcta operatividad y seguridad.

\section{5. Ética y conflicto de intereses}

El autor declara que han cumplido totalmente con todos los requisitos éticos y legales pertinentes, tanto durante el estudio como en la producción del manuscrito; que no hay conflictos de intereses de ningún tipo; que todas las fuentes financieras se mencionan completa y claramente en la sección de agradecimientos; y que están totalmente de acuerdo con la versión final editada del artículo.

\section{Agradecimientos}

A los funcionarios del Muelle Municipal Centenario, Luis Odar Cumpa y Oscar Barrantes Novoa, por la información brindada; a María López, Leónidas Loayza y Alexander Vásquez, por su apoyo en las salidas al campo. Este trabajo se realizó con autofinanciamiento. Se agradece

\begin{tabular}{|c|c|c|c|c|}
\hline 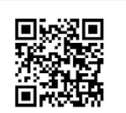 & (c) (1) (9) & $\underset{\text { AMBIENTAIES }}{\Leftrightarrow}$ & $\frac{O \%}{2)}$ & 112 \\
\hline
\end{tabular}




\section{Revista de CIENCIAS AMBIENTALES Tropical Journal of Environmental Sciences}

Revista de Ciencias Ambientales (Trop J Environ Sci) e-ISSN: 2215-3896 (Enero-Julio, 2021) . Vol 55(1): 86-117 DOI: https://doi.org/10.15359/rca.55-1.5 Open Access: www.revistas.una.ac.cr/ambientales e-mail: revista.ambientales@una.ac.cr Loayza-Aguilar R.

también a la Revista y a las personas dictaminadoras externas, por los múltiples aportes realizados al documento.

\section{Referencias}

Allan, J. y Komar, P. (2006). Climate Controls on US West Coast Erosion Processes. Journal of Coastal Research, (223): 511-529. https://doi.org/10.2112/03-0108.1

Basurco, F. (2000). Propuestas técnicas para disminuir la contaminación atmosférica proveniente de la industria pesquera en la bahía El Ferrol. En: III parte del Diagnóstico ambiental y propuestas técnicas para la recuperación de la bahía El Ferrol (pp. 119-126). Lima, Perú: Consejo Nacional del Ambiente (CONAM).

Comisión Europea. (2005). Vivir con la erosión costera en Europa - Sedimentos y espacio para la sostenibilidad. P. Doody, M. Ferreira, S. Lombardo, I. Lucius, R. Misdorp, H. Niesing, A. Salman, M. Smallegange, J. Serra, E. Roca, P. Fernández y C. Pérez (eds.). Luxemburgo: Oficina para las Publicaciones Oficiales de las Comunidades Europeas. 40 pp.

Comisión Técnica Multisectorial [CTM]. (29 de agosto de 2012). Plan de recuperación ambiental de la bahía El Ferrol (Chimbote, Perú). Diario Oficial El Peruano. http://www.minam.gob. pe/wp-content/uploads/2013/07/rs_004-2012-minam_aprueban_plan_recuperacion_ambiental_bahia_el_ferrol2.pdf

Correa, I.; Ríos, A.; González, D.; Toro, M.; Ojeda, G. y Restrepo, I. (2007). Erosión litoral entre Arboletes y Punta San Bernardo, costa Caribe Colombiana. Boletín de Geología, 29(2), 115-129.

Cuenca y Desarrollo. (1998). El Niño en el valle del Santa - Lacramarca. Bol. Mesa ONGs del Santa para el Manejo Integrado de la Cuenca, 2(3), 6-9.

Dirección de Hidrografía y Navegación [DHN]. (1979). Mapa cartográfico Perú HIDRONAV 1313.

Dirección de Hidrografía y Navegación [DHN]. (1980). Carta Náutica Perú Hidronav 1313, 2. edic., jul. de 1980.

Dirección de Hidrografía y Navegación [DHN]. (2003). Estudio oceanográfico bahía FerrolChimbote. [Informe Técnico]. Lima, Perú.

Dirección de Hidrografía y Navegación [DHN]. (2008). Estudio de la erosión y sedimentación en la bahía Ferrol - Chimbote.

Dirección de Hidrografía y Navegación [DHN]. (2009). Carta Náutica Perú Hidronav 2123, 1. edic., set. de 2009.

\begin{tabular}{|c|c|c|}
\hline 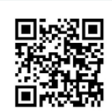 & (c) (1) (9) & 113 \\
\hline
\end{tabular}




\section{Revista de CIENCIAS AMBIENTALES Tropical Journal of Environmental Sciences}

Revista de Ciencias Ambientales (Trop J Environ Sci) e-ISSN: 2215-3896 (Enero-Julio, 2021) . Vol 55(1): 86-117 DOI: https://doi.org/10.15359/rca.55-1.5

Open Access: www.revistas.una.ac.cr/ambientales e-mail: revista.ambientales@una.ac.cr Loayza-Aguilar R.

Dirección de Hidrografía y Navegación [DHN]. (2013). Manual de procedimientos para la medición de olas, HIDRONAV - 5137. Normas técnicas hidrográficas no. 8, Oceanografía, 1. ed.

Dirección de Hidrografía y Navegación [DHN]. (2016). Carta Náutica Perú Hidronav 2123, 2. edic., oct. de 2016.

Dirección de Hidrografía y Navegación [DHN]. (2019). Estudio de Modelo numérico de la Bahía El Ferrol y escenarios de erosión y sedimentación de la bahía. Exposición de la Dirección de Hidrografía y Navegación (DIHIDRONAV) de la Marina de Guerra del Perú, 25 de octubre de 2019. Chimbote, Perú.

Guido, G.; Ramírez, A.; Godínez, L.; Cruz, S. y Juárez, A. (2009). Estudio de la erosión costera en Cancún y la rivera Maya, México. Av. Recur. Hidraul., (20), 41-56.

Guzmán, M.; Ganosa, F.; Velazco, F. y Jacinto, M. (2002). Prospección para la evaluación de las condiciones ambientales y sedimentológicas en la bahía El Ferrol - Chimbote 22 al 25 junio 2002. [Inf. Interno IMARPE].

Guzmán, E. (2006a). Modelamiento de corrientes superficiales por viento y marea en la bahía Ferrol - Chimbote (tesis para título de ingeniero). Univ. Nac. Mayor San Marcos, Lima, Perú.

Guzmán, E. (2006b). Modelos Numéricos: Una herramienta para el estudio de los procesos oceánicos y costeros. Bitácora Hidrográfica, (2), 16-17.

Guzmán, E. (2014). Modelamiento de la dispersión de contaminantes pasivos en la bahía Ferrol - Chimbote (tesis de magíster). Univ. Nac. Mayor San Marcos, Lima, Perú.

Guzmán, E. (s. f.). Aplicación del modelo de transporte de sedimentos UNIBEST CL 6.0 a la bahía de Miraflores. http://www.naylamp.dhn.mil.pe/oceano/unibest/unibest.pdf

Klein, R. y Nicholls, R. (1999). Assessment of coastal vulnerability to climate change. Ambio, 28(2), 182-187.

Kombiadou, K.; Krestenitis, Y.; Baltikas, V. y Kalantzi, G. (2012). Coastal Erosion Problems in Katerini: Methods and Measures. Protection and Restoration of the Environment XI, July 3-6, Thessaloniki, Greece, pp. 758-767.

Kuramoto, J. (2005). El clúster pesquero de Chimbote: Acción conjunta limitada y la tragedia de los recursos colectivos. Lima, Perú: Grupo de Análisis para el Desarrollo (GRADE).

Lanza, S. y Randazzo, G. (2011). A project for a protected re-nourishment of the coastline of Giardini Naxos, the touristic beach in the neighboring area of Taormina (North - Eastern Sicily). Littoral 2011, 1-10. https://doi.org/10.1051/litt/201105001

\begin{tabular}{|c|c|c|}
\hline 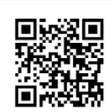 & (c) (1) (9) & 114 \\
\hline
\end{tabular}




\section{Revista de CIENCIAS AMBIENTALES Tropical Journal of Environmental Sciences}

Revista de Ciencias Ambientales (Trop J Environ Sci) e-ISSN: 2215-3896 (Enero-Julio, 2021) . Vol 55(1): 86-117 DOI: https://doi.org/10.15359/rca.55-1.5

Open Access: www.revistas.una.ac.cr/ambientales e-mail: revista.ambientales@una.ac.cr Loayza-Aguilar R.

Larrea, E. (1994). Identificación y diagnóstico de proyectos de riego con aguas servidas tratadas de la ciudad de Chimbote. Lima, Perú: Minist. Agric.

Ley Recursos Hídricos 29338. (31 de marzo de 2009). Diario El Peruano. Lima, Perú.

Livesey \& Henderson Consulting Engineers [LHCE]. (1972). Estudio del sistema portuario de Chimbote: Primera etapa. Estudios de alternativas. Vol. 2 Planos. Lima, Perú: CRYRZA / Minist. Transp. y Comun.

Loayza, R. (1998). Génesis de la perturbación de la bahía El Ferrol. Chimbote, Perú: Univ. Nac. Santa / Inst. Ecol. Natura. 104 p.

Loayza, R. (2002a). Contaminación y erosión en la bahía "El Ferrol” (Chimbote, Perú). Bol. de Lima, 24(130), 113-133.

Loayza, R. (2002b). Situación del litoral de la bahía "El Ferrol" (Chimbote, Perú). Comisión Técnica Multisectorial de Alto Nivel Encargada de Proponer el Plan de Recuperación Ambiental de la bahía "El Ferrol" [CTM]: Informe de recorrido 31.10.2002. Chimbote, Perú: Edit. Univ. Nac. Santa.

Ministerio del Ambiente [MINAM]. (2012). Informe de la Evaluación Ambiental de Playa afectada por la presencia de residuos sólidos contaminantes en la Bahía El Ferrol (Chimbote-Ancash). INFORME 4l-2012- OEFA /DE.

Ministerio del Ambiente [MINAM]. (2016). Lineamientos para el Manejo Integrado de las Zonas Marino Costeras. Lima, Perú.

Ministerio de la Producción [PRODUCE]. (28 de octubre de 2007). Decreto Supremo 020-2007-PRODUCE que aprueba Plan Ambiental Complementario Pesquero (PACPE) en la Bahía El Ferrol. Diario El Peruano, pp. 356192-356195. Lima, Perú.

Ministerio dela Producción [PRODUCE]. (30 de abril de2008). Decreto Supremo 010-2008-PRODUCE que aprueba Límites Máximos Permisibles (LMP) para la industria de harina y aceite de pescado y normas complementarias. Diario El Peruano, pp. 371510-371512. Lima, Perú.

Neyra, R. (2015). Análisis de la aplicación de sistemas de frío en la captura y transporte de anchoveta (Engraulis ringens) y su influencia en los parámetros de procesamiento de la harina de pescado (tesis para título de ingeniero pesquero). Univ. Nac. San Agustín de Arequipa, Arequipa, Perú.

Oficina Nacional de Evaluación de Recursos Naturales [ONERN]. (1972). Inventario, evaluación y uso racional de los recursos naturales de la costa: cuencas de los ríos Santa, Lacramarca y Nepeña. Vol. I. ONERN. Lima, Perú.

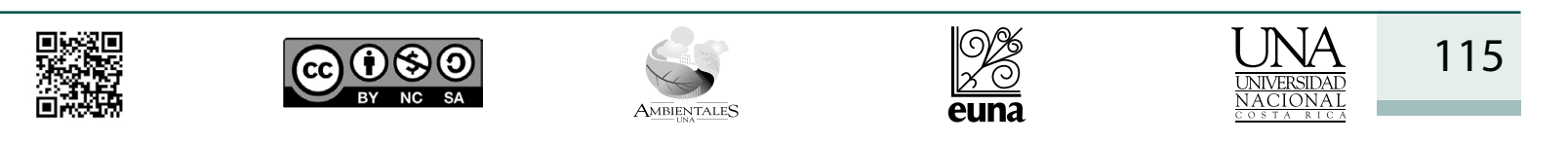




\section{Revista de CIENCIAS AMBIENTALES Tropical Journal of Environmental Sciences}

Revista de Ciencias Ambientales (Trop J Environ Sci) e-ISSN: 2215-3896 (Enero-Julio, 2021) . Vol 55(1): 86-117 DOI: https://doi.org/10.15359/rca.55-1.5

Open Access: www.revistas.una.ac.cr/ambientales e-mail: revista.ambientales@una.ac.cr Loayza-Aguilar R.

Ojeda, J. (2000). Métodos para el cálculo de la erosión costera. Revisión, tendencias y propuesta. Bol. de la AGE, (30),103-118.

Ojeda, G.; Alcañiz, J. y Le, Y. (2008). Differences in aggregate stability due to sewage sludge treatments on a Mediterranean calcareous soil. Agriculture, Ecosystems and Environment, 125, 48-56. https://doi.org/10.1016/j.agee.2007.11.005

Polar, M. (2016). Uso de la teledetección para identificar los cambios espacio-temporales de la morfología de la línea costera peruana. En Libro de Resúmenes, V Congreso de Ciencias del Mar del Perú. Lambayeque, Perú: Universidad Nacional Pedro Ruiz Gallo.

Prasad, D. y Kumar, N. (2014). Coastal Erosion Studies - A Review. International Journal of Geosciences, 5, 341-345. https://doi.org/10.4236/ijg.2014.53033

Ramos, C. (2010). Modelamiento de procesos costeros para determinar Zonas de erosión y sedimentación de playas. Bitácora Hidrográfica, (7), 14-17.

Ramos, C. (2014). Simulación numérica de la modificación de las olas en la Bahía de Miraflores (tesis para título de ingeniero). Univ. Nac. Mayor San Marcos, Lima, Perú.

Ramos, C. (2017). Simulación de transporte de sedimentos en la bahía Ferrol, Chimbote (tesis de maestría). Univ. Nac. Mayor San Marcos, Lima, Perú.

Rangel-Buitrago, N. y Posada-Posada, B. (2013). Determinación de la vulnerabilidad y el riesgo costero mediante la aplicación de herramientas SIG y métodos multicriterio en la línea de costa, Caribe colombiano. Revista Intrópica, 8, 29-42.

Ricaurte-Villota, C. (2015). Erosión de las zonas costeras y alternativas de mitigación. Programa de Geociencias Marinas y Costeras INVEMAR, I Simposio: Retos, Diálogos y Cooperación para la Sostenibilidad del Mar Caribe Puerto España - Trinidad y Tobago, del 23 al 24 de noviembre de 2015. http://www.acs-aec.org/sites/default/files/erosion_-ricaurte-villota.pdf

Rodríguez, R. y Beltrán, H. (2012). Estudio de los procesos de erosión-sedimentación playa El Espino. República de El Salvador, San Salvador: Ministerio de Medio Ambiente y Recursos Naturales.

Roig-Munar, F; Martín, J.; Rodríguez, A. y Blázquez, M. (2018). Restauración de sistemas dunares en las islas Baleares (2000-2017): una visión crítica. Investigaciones Geográficas, (69), 119-136. https://doi.org/10.14198/INGEO2018.69.08

San Martín, L.; Marcomini, S. y López, R. (2015). Vulnerabilidad a la erosión costera entre las localidades de Mar de Cobo y Mar Chiquita, provincia de Buenos Aires, Argentina. https:// www.researchgate.net/publication/273886716

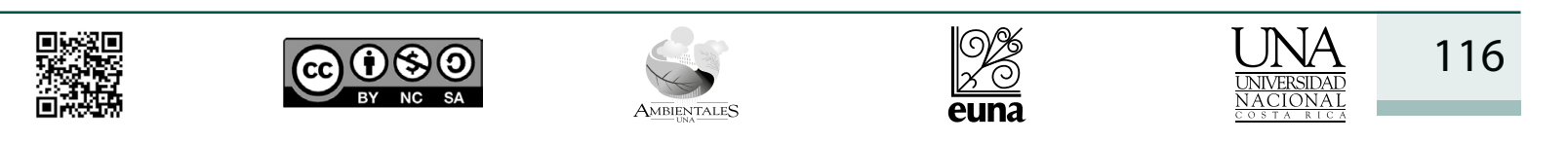




\section{Revista de CIENCIAS AMBIENTALES Tropical Journal of Environmental Sciences}

Revista de Ciencias Ambientales (Trop J Environ Sci) e-ISSN: 2215-3896 (Enero-Julio, 2021) . Vol 55(1): 86-117 DOI: https://doi.org/10.15359/rca.55-1.5 Open Access: www.revistas.una.ac.cr/ambientales e-mail: revista.ambientales@una.ac.cr Loayza-Aguilar R.

Saavedra, M. y Guzmán, E. (2003). Estudio de corrientes superficiales en la bahía Ferrol aplicando el modelo POM. http://www.naylamp.dhn.mil.pe/oceano/pom/pom_ferrol.pdf

Sánchez, G.; Enríquez, E. y García, V. (2008). Bahías El Ferrol y Coishco, Chimbote, Perú: Evaluación ambiental en abril y julio 2002. Informe IMARPE, 35(1), 7-25.

Sánchez, G.; Blas, N. y Chau, G. 2010. Informe nacional sobre el estado del ambiente marino del Perú. [Informe de consultoría, convenio IMARPE-CPPS]. Callao, Perú.

Sanjaume, E.; Gracia, F. y Flor, G. (2011). Introducción a la geomorfología de sistemas dunares. En E. Sanjaume y F. Gracia (eds.), Las dunas en España (pp. 13-63). Puerto Real, España: Sociedad Española de Geomorfología.

Sulmont, D. (2006). El boom de Chimbote.

Takahashi, K.; Mosquera, K.; Aparco, J.; Ramos, Y.; Fajardo, J. y Montes, I. (2014). Evaluación del posible impacto de la variabilidad y cambio climático en el nivel del mar en la costa de Lima. Instituto Geofísico de Perú. http://www.met.igp.gob.pe/proyectos/manglares/estudio_ nivel_mar_IGP.pdf

Takahashi, K. (2017). Fenómeno El Niño: “Global” vs “Costero”. Instituto Geofísico del Perú, "Generación de información y monitoreo del Fenómeno El Niño". Boletín Técnico, 4(4), 1-7.

Teves, E. (1999). Plan de manejo de recursos costeros para la bahía El Ferrol, Chimbote - Ancash. Lima, Perú: Consejo Nacional del Ambiente. http://www2.congreso.gob.pe/sicr/cendocbib/ con4_uibd.nsf/FDCF6753EEEE4C2205257D33006224BF/\$FILE/1_PLanManejoRecursosCosterosBahiaChimbote.pdf

Tresierra, A.; García, V.; Huerto, M.; Berru, P.; Reyes, D. y Cervantes, C. (2007). Bahía El Ferrol, Chimbote, Perú: una visión integral de sus recursos vivos y su ambiente 2001-2005. Inf. Inst. Mar Perú, 34(1), 25-68.

Tsoukala, V.; Katsardi, V.; Hadjibiros, K. y Moutzouris, C. (2015). Beach erosion and consequential impacts due to the presence of harbours in sandy beaches in Greece and Cyprus. Environ. Process., 2 (suppl 1), S55-S71. https://doi.org/10.1007/s40710-015-0096-0

Williams, A.; Rangel-Buitrago, N.; Pranzini, E. y Anfuso, G. (2017). The management of coastal erosion. Ocean \& Coastal Management, 30, 1-17. https://doi.org/10.1016/j. ocecoaman.2017.03.022

\begin{tabular}{|c|c|c|c|c|c|}
\hline 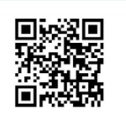 & (c) (1) (5) () & 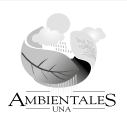 & $\frac{10 \%}{20}$ & $\frac{\text { UNA }}{\frac{\text { UNIVERSIDAD }}{\text { NACIONAL }}}$ & 117 \\
\hline
\end{tabular}

